\title{
In situ determination of the remote sensing reflectance: an inter-comparison
}

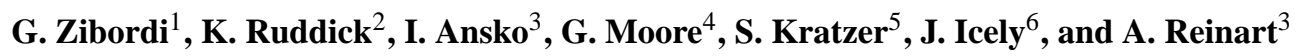 \\ ${ }^{1}$ Institute for Environment and Sustainability, Joint Research Centre, Ispra, Italy \\ ${ }^{2}$ Royal Belgian Institute of Natural Sciences, Management Unit of the North Sea Mathematical Models, Brussels, Belgium \\ ${ }^{3}$ Tartu Observatory, Estonia \\ ${ }^{4}$ Bio-Optika, Crofters, Middle Dimson, Gunnislake, UK \\ ${ }^{5}$ Stockholm University, Department of Systems Ecology, Sweden \\ ${ }^{6}$ Sagremarisco Lda, Vila do Bispo, Portugal \\ Correspondence to: G. Zibordi (giuseppe.zibordi@jrc.ec.europa.eu)
}

Received: 15 February 2012 - Published in Ocean Sci. Discuss.: 7 March 2012

Revised: 15 June 2012 - Accepted: 4 July 2012 - Published: 6 August 2012

\begin{abstract}
Inter-comparison of data products from simultaneous measurements performed with independent systems and methods is a viable approach to assess the consistency of data and additionally to investigate uncertainties. Within such a context the inter-comparison called Assessment of In Situ Radiometric Capabilities for Coastal Water Remote Sensing Applications (ARC) was carried out at the Acqua Alta Oceanographic Tower in the northern Adriatic Sea to explore the accuracy of in situ data products from various in- and above-water optical systems and methods. Measurements were performed under almost ideal conditions, including a stable deployment platform, clear sky, relatively low sun zenith angles and moderately low sea state. Additionally, all optical sensors involved in the experiment were inter-calibrated through absolute radiometric calibration performed with the same standards and methods. Inter-compared data products include spectral waterleaving radiance $L_{\mathrm{w}}(\lambda)$, above-water downward irradiance $E_{\mathrm{d}}\left(0^{+}, \lambda\right)$ and remote sensing reflectance $R_{\mathrm{rs}}(\lambda)$. Data products from the various measurement systems/methods were directly compared to those from a single reference system/method. Results for $R_{\mathrm{rs}}(\lambda)$ indicate spectrally averaged values of relative differences comprised between -1 and $+6 \%$, while spectrally averaged values of absolute differences vary from approximately $6 \%$ for the above-water systems/methods to $9 \%$ for buoy-based systems/methods. The agreement between $R_{\mathrm{rS}}(\lambda)$ spectral relative differences and estimates of combined uncertainties of the inter-compared systems/methods is noteworthy.
\end{abstract}

\section{Introduction}

Climate studies largely rely on environmental indices derived from remote sensing data (e.g. Behrenfeld et al., 2006; Achard et al., 2002; Kaufman and Tanré, 2002; Stroeve et al., 2007). Satellite ocean color data are also increasingly applied for coastal and inland water management, including water quality monitoring, harmful algal bloom detection and sediment transport studies (Brando and Dekker, 2003; Stumpf and Tomlinson, 2005; Ruddick et al., 2008). However, the confident use of these data requires the quantification of their uncertainties. This is generally accomplished through the comparison of satellite products with in situ reference measurements. In the case of satellite ocean color, the spectral remote sensing reflectance $R_{\mathrm{rs}}$ determined from topof-atmosphere radiance is the primary data product used for the generation of higher level products such as chlorophyll $a$ concentration ( $\mathrm{Chl} a$ ). As a consequence, access to accurate in situ $R_{\mathrm{rs}}$ is essential for the assessment of primary data products from satellite ocean color missions.

In situ $R_{\mathrm{rs}}$ data are obtained through in-water and abovewater optical measurement systems. Both approaches rely on a number of methods frequently tied to a variety of instruments characterized by different design and performances. This aspect together with a diverse implementation of measurement methods, the application of different processing schemes, and the use of various sources and methods for the absolute radiometric calibration of field instruments may 
lead to unpredictable uncertainties affecting the assessment of satellite products.

The quantification and the successive reduction of uncertainties for in situ measurements is thus a major challenge for ocean color scientists actively involved in field radiometry. Basic tasks include the precise implementation and application of established measurement and analysis methods, and additionally an investigation and quantification of each source of uncertainty in primary data products. Best practice suggests the verification of each measurement and processing step through inter-comparison exercises.

This work summarizes results from a radiometric intercomparison performed in the northern Adriatic Sea with the main objective of evaluating the agreement of in situ $R_{\mathrm{rs}}$ products determined through the application of independent measurement systems and methods.

\section{The inter-comparison}

Inter-comparison activities are essential to evaluate the performance of independent measurement methods and also the ability of individuals to properly implement them (e.g. Thome et al., 1998; Hooker et al., 2002a; Barton et al., 2004). A major requirement for field inter-comparisons is the need for performing measurements with different systems/methods under almost identical conditions. In the case of optical oceanography, this is better achieved with the use of fixed deployment platforms instead of ships. In fact, grounded platforms offer the major advantage of deploying instruments under controlled geometries not affected by superstructure drift and roll. This favourable situation is easily achieved at the Acqua Alta Oceanographic Tower (AAOT) in the northern Adriatic Sea (e.g. Zibordi et al., 1999, 2009a; Hooker and Zibordi, 2005).

The inter-comparison activity presented and discussed in this work focuses on a variety of measurement systems and methods applied to produce in situ data for the validation of marine primary radiometric products for the Medium Resolution Imaging Spectrometer (MERIS) onboard the Envisat platform of the European Space Agency (ESA). The intercomparison, called Assessment of In Situ Radiometric Capabilities for Coastal Water Remote Sensing Applications (ARC) was conceived within the framework of the MERIS Validation Team (MVT) and supported by ESA in the context of international activities promoted by the Working Group on Calibration and Validation (WGCV), Infrared and Visible Optical Systems (IVOS) subgroup of the Committee on Earth Observation Satellites (CEOS).

ARC activities comprise two successive phases carried out during July 2010. In the first phase, field measurements were carried out at the AAOT during four days characterized by favourable illumination and sea state conditions. In the second phase, the optical sensors previously deployed at the AAOT were inter-calibrated at the Joint Research Centre
(JRC). This inter-calibration was achieved through the absolute radiometric calibration of the optical sensors by using identical laboratory standards and methods, with the exception of one system (see Sect. 3.3.3) also calibrated at the JRC using the same standards and methods, but at a different time. Data products included in the inter-comparison were then all computed from data calibrated (or corrected) using consistently determined radiometric coefficients.

The inter-comparison of data products from different measurement systems and methods is here performed, relying on data from a single system/method considered as the reference because of its well documented performances and longstanding application to the validation of satellite ocean color products. Due to the variety of multispectral and hyperspectral sensors included in the inter-comparison, the data analysis has been restricted to the center-wavelengths of major interest for satellite ocean color: 412, 443, 490, 510, 555, and $665 \mathrm{~nm}$. The presentation of results is supported by uncertainty budgets quantified for each system/method.

\section{Measurement systems and methods}

The ARC inter-comparison includes an assortment of in- and above-water measuring systems and methods. To rationalize their description, the basic elements common to generic methods (i.e. in- and above-water) are hereafter summarized, then details on each measurement system and method are provided. It is anticipated that the analysis of results is focused on $R_{\text {rs }}$ determined according to its simplest definition (see Sect. 3.1) without applying any correction for the anisotropy of in-water radiance distribution (i.e. the bidirectional effects). In fact, the objective of this work is to quantify differences among fundamental radiometric products derived from the application of various systems and methods; the use of the same scheme to account for bidirectional effects would not impact the comparison, while the application of different schemes is out of the scope of the study. In line with such a strategy, the dependence on the viewing geometry of above-water measurements (also depending on the inwater radiance distribution) has been addressed by applying an identical correction scheme for all considered methods.

\subsection{Overview on in-water measurements}

In-water radiometry relies on subsurface continuous or fixeddepth profiles of upwelling radiance $L_{\mathrm{u}}(z, \lambda, t)$, downward irradiance $E_{\mathrm{d}}(z, \lambda, t)$ and occasionally also upward irradiance $E_{\mathrm{u}}(z, \lambda, t)$ at depth $z$, wavelength $\lambda$ and time $t$. The above-water downward irradiance $E_{\mathrm{d}}\left(0^{+}, \lambda, t\right)$ is also measured to complement the in-water data. These latter data are used to extrapolate to $0^{-}$(i.e. just below the water surface) the radiometric quantities which cannot be directly measured because of wave perturbations. Above-water downward irradiance data are used to minimize the effects of illumination 
changes on in-water radiometric measurements during data collection.

In-water continuous profiles of radiometric quantities result generally from measurements performed with optical sensors operated on profiling systems (e.g. winched or freefall). Due to wave focusing and defocusing, the accuracy of sub-surface radiometric products largely depends on the sampling depth interval and on the depth resolution (Zaneveld et al., 2001; D'Alimonte et al., 2010). Thus, highly accurate inwater radiometric products can only be determined by sampling near the surface (especially in coastal regions due to possible vertical non-homogeneities in the optical properties of seawater), and by producing a large number of measurements per unit depth not significantly affected by tilt (Zibordi et al., 2004a).

In-water fixed-depth profiles mostly result from the use of optical sensors operated on buoys at nominal depths. These buoy-based systems generally provide the capability of measuring $L_{\mathrm{u}}(z, \lambda, t), E_{\mathrm{d}}(z, \lambda, t)$ and possibly also $E_{\mathrm{u}}(z, \lambda, t)$ at multiple depths (typically between 1 and $10 \mathrm{~m}$ ), in addition to $E_{\mathrm{d}}\left(0^{+}, \lambda, t\right)$. By neglecting the effects of system tilt, the accuracy of radiometric products determined with buoy-based systems is a function of the discrete depths selected for the optical sensors, the acquisition rate and the duration of logging intervals (Zibordi et al., 2009a).

The same data reduction process is in principle applicable to both fixed-depth and continuous profile radiometric data $\Im(z, \lambda, t)$ (i.e. $L_{\mathrm{u}}(z, \lambda, t), E_{\mathrm{u}}(z, \lambda, t)$ and $\left.E_{\mathrm{d}}(z, \lambda, t)\right)$. The initial step, leading to minimization of perturbations created by illumination change during data collection, is performed according to:

$\Im_{0}\left(z, \lambda, t_{0}\right)=\frac{\Im(z, \lambda, t)}{E_{\mathrm{d}}\left(0^{+}, \lambda, t\right)} E_{\mathrm{d}}\left(0^{+}, \lambda, t_{0}\right)$,

where $\Im_{0}\left(z, \lambda, t_{0}\right)$ indicates radiometric values as if they were all taken at the same time $t_{0}$, and $E_{\mathrm{d}}\left(0^{+}, \lambda, t_{0}\right)$ specifies the above-water downward irradiance at time $t_{0}$ (with $t_{0}$ generally chosen to coincide with the beginning of the acquisition sequence).

Omitting the variable $t$, the sub-surface quantities $\Im_{0}\left(0^{-}, \lambda\right)$ (i.e. $L_{\mathrm{u}}\left(0^{-}, \lambda\right), E_{\mathrm{u}}\left(0^{-}, \lambda\right)$ and $\left.E_{\mathrm{d}}\left(0^{-}, \lambda\right)\right)$ are then determined as the exponentials of the intercepts resulting from the least-squares linear regressions of $\ln \Im_{0}(z, \lambda)$ versus $z$ within the extrapolation interval identified by $z_{1}<z<z_{2}$ and chosen to satisfy the requirement of linear decay of $\ln \Im_{0}(z, \lambda)$ with depth. The negative values of the slopes of the regression fits are the so-called diffuse attenuation coefficients $K_{\Im}(\lambda)$ (i.e. $K_{l}(\lambda), K_{\mathrm{u}}(\lambda)$ and $K_{\mathrm{d}}(\lambda)$ determined from $L_{\mathrm{u}}(z, \lambda, t), E_{\mathrm{u}}(z, \lambda, t)$ and $E_{\mathrm{d}}(z, \lambda, t)$ values, respectively, from the selected extrapolation interval).

The radiometric quantity of major relevance here is the so-called water-leaving radiance $L_{\mathrm{w}}(\lambda)$ in units of $\mathrm{mW} \mathrm{cm}{ }^{-2} \mu \mathrm{m}^{-1} \mathrm{sr}^{-1}$. This is the radiance leaving the sea quantified just above the surface from:

$L_{\mathrm{w}}(\lambda)=0.543 L_{\mathrm{u}}\left(0^{-}, \lambda\right)$,

where the factor 0.543 , derived assuming the seawater refractive index is independent of wavelength (Austin, 1974), accounts for the reduction in radiance from below to above the water surface.

A second radiometric quantity central to this study is the remote sensing reflectance $R_{\mathrm{rs}}(\lambda)$ in units of $\mathrm{sr}^{-1}$, given by:

$R_{\mathrm{rs}}(\lambda)=\frac{L_{\mathrm{w}}(\lambda)}{E_{\mathrm{d}}\left(0^{+}, \lambda\right)}$,

with $E_{\mathrm{d}}\left(0^{+}, \lambda\right)$ in units of $\mathrm{mW} \mathrm{cm} \mathrm{cm}^{-2} \mu \mathrm{m}^{-1}$.

$R_{\mathrm{rs}}(\lambda)$ is thus a quantity corrected for illumination conditions depending on sun zenith angle, Sun-Earth distance and atmospheric transmittance (Mueller et al., 2002).

\subsection{Overview on above-water measurements}

Above-water methods generally rely on measurements of (i) total radiance from above the sea $L_{\mathrm{T}}(\theta, \Delta \phi, \lambda)$ (that includes water-leaving radiance as well as sky- and sunglint contributions); (ii) the sky radiance $L_{i}\left(\theta^{\prime}, \Delta \phi, \lambda\right)$; and (iii) usually also $E_{\mathrm{d}}\left(0^{+}, \lambda\right)$. The measurement geometry is defined by the sea-viewing angle $\theta$, the sky-viewing angle $\theta^{\prime}$ and the difference between sun and sensor azimuth angles, $\Delta \phi=\phi_{0}-\phi$ (Deschamps et al., 2004; Hooker et al., 2004; Zibordi et al., 2004b). The accurate determination of $L_{\mathrm{w}}(\lambda)$ then depends on the capability of minimizing glint contributions through the use of suitable measurement geometries (Mobley, 1999), and additionally, the application of statistical filtering schemes to $L_{\mathrm{T}}$ (Hooker et al., 2002a; Zibordi et al., 2002b), or physically-based correction methods relying on known reflectance properties of seawater in the near-infrared spectral region (Ruddick et al., 2006), or alternatively, polarisers to directly reduce sky- and sun-glint (Fougnie et al., 1999).

In the case of non-polarized systems, measurements of $L_{\mathrm{T}}(\theta, \Delta \phi, \lambda)$ and $L_{i}\left(\theta^{\prime}, \Delta \phi, \lambda\right)$ for the determination of $L_{\mathrm{w}}(\lambda)$ are generally performed at $\theta=40^{\circ}$ and $\theta^{\prime}=140^{\circ}$, with $\Delta \phi$ chosen between $+90^{\circ}$ and $+135^{\circ}$ or alternatively $-90^{\circ}$ and $-135^{\circ}$. The value of $\Delta \phi= \pm 135^{\circ}$ is considered the most appropriate (see Mobley, 1999). However, its application must be regarded with special care because it may more likely lead to measurements significantly affected by the shadow cast by the deployment superstructure in the antisolar region (i.e. nearby the sea area seen by the sensor).

The water-leaving radiance $L_{\mathrm{w}}(\theta, \Delta \phi, \lambda)$ for a given viewing geometry is computed as:

$$
\begin{aligned}
L_{\mathrm{w}}(\theta, \Delta \phi, \lambda)= & L_{\mathrm{T}}(\theta, \Delta \phi, \lambda) \\
& -\rho\left(\theta, \Delta \phi, \theta_{0}, W\right) L_{i}\left(\theta^{\prime}, \Delta \phi, \lambda\right),
\end{aligned}
$$

where $\rho\left(\theta, \Delta \phi, \theta_{0}, W\right)$ is the sea surface reflectance that can be theoretically determined as a function of the measurement 
Table 1. Summary of codes assigned to measurement systems/methods together with relevant references and responsible institutes.

\begin{tabular}{llll}
\hline $\begin{array}{l}\text { System/method } \\
\text { code (type) }\end{array}$ & Measurement system & $\begin{array}{l}\text { References for } \\
\text { system/method }\end{array}$ & Responsible institutes(s) \\
\hline $\begin{array}{l}\text { WiSPER } \\
\text { In-Water) }\end{array}$ & $\begin{array}{l}\text { Wire-Stabilized Profiling } \\
\text { Environmental Radiometer }\end{array}$ & Zibordi et al. (2004a, 2009a) & Joint Research Centre \\
\hline $\begin{array}{l}\text { TACCS-S } \\
\text { In-Water) }\end{array}$ & $\begin{array}{l}\text { Tethered Attenuation Coef- } \\
\text { ficient Chain Sensor }\end{array}$ & $\begin{array}{l}\text { Kratzer et al. (2008), Moore } \\
\text { et al. (2010) }\end{array}$ & $\begin{array}{l}\text { Stockholm University } \\
\text { \& Bio-Optika }\end{array}$ \\
\hline $\begin{array}{l}\text { TACCS-P } \\
\text { In-Water) }\end{array}$ & $\begin{array}{l}\text { Tethered Attenuation Coef- } \\
\text { ficient Chain Sensor }\end{array}$ & Moore et al. (2010) & Sagremarisco Lda \& Bio-Optika \\
\hline $\begin{array}{l}\text { SeaPRISM } \\
\text { (Above-Water) }\end{array}$ & $\begin{array}{l}\text { SeaWiFS Photometer Revi- } \\
\text { sion for Incident Surface }\end{array}$ & Zibordi et al. (2004b, 2009c) & Joint Research Centre \\
\hline $\begin{array}{l}\text { TRIOS-B } \\
\text { (Above-Water) }\end{array}$ & $\begin{array}{l}\text { RAMSES Hyperspectral } \\
\text { Radiometers }\end{array}$ & Ruddick et al. (2005, 2006) & $\begin{array}{l}\text { Management Unit of the North } \\
\text { Rea Mathematical Models }\end{array}$ \\
\hline $\begin{array}{l}\text { TRIOS-E } \\
\text { (Above-Water) }\end{array}$ & $\begin{array}{l}\text { RAMSES Hyperspectral } \\
\text { Radiometers }\end{array}$ & Ruddick et al. (2005, 2006) & Tartu Observatory \\
\hline
\end{tabular}

geometry identified by $\theta, \Delta \phi$, sun zenith $\theta_{0}$, and of the sea state conveniently expressed through the wind speed $W$.

The water-leaving radiance $L_{\mathrm{w}}(\lambda)$ for a nadir-view direction is then determined by:

$L_{\mathrm{w}}(\lambda)=L_{\mathrm{w}}(\theta, \Delta \phi, \lambda) \frac{\Re_{0}}{\Re(\theta, W)} \frac{Q\left(\theta, \Delta \phi, \theta_{0}, \lambda, \tau_{\mathrm{a}}, \mathrm{IOP}\right)}{Q_{n}\left(\theta_{0}, \lambda, \tau_{\mathrm{a}}, \mathrm{IOP}\right)}$,

where $\mathfrak{K}(\theta, W)$ and $\mathfrak{R}_{0}$ (i.e. $\Re(\theta, W)$ at $\theta=0$ ) account for the sea surface reflectance and refraction, and depend mainly on $\theta$ and $W$ (Morel et al., 2002). The spectral quantities $Q\left(\theta, \Delta \phi, \theta_{0}, \lambda, \tau_{\mathrm{a}}, \mathrm{IOP}\right)$ and $Q_{n}\left(\theta_{0}, \lambda, \tau_{\mathrm{a}}, \mathrm{IOP}\right)$ are the Qfactors at viewing angle $\theta$ and at nadir (i.e. $\theta=0$ ), respectively, describing the anisotropic distribution of the in-water radiance. Publically available Q-factors (Morel et al., 2002) have been theoretically determined as a function of $\theta, \Delta \phi, \theta_{0}$, the atmospheric optical properties (conveniently expressed through the aerosol optical thickness $\tau_{\mathrm{a}}$, even though assumed constant), and the seawater inherent optical properties IOPs (conveniently expressed through Chl $a$ for oceanic waters).

The remote sensing reflectance is then computed from Eq. (3) using measured or theoretical values of $E_{\mathrm{d}}\left(0^{+}, \lambda\right)$.

\subsection{Details on individual measurement systems and methods}

Systems and methods included in the ARC inter-comparison are listed in Table 1 together with the institutes responsible for data collection, processing and quantifying system/method uncertainties. Additionally, Table 2 provides details for each system in conjunction with the main input parameters required for data processing.

\subsubsection{WiSPER}

The Wire-Stabilized Profiling Environmental Radiometer (WiSPER) is a winched system deployed through a custombuilt profiling rig at a speed of $0.1 \mathrm{~m} \mathrm{~s}^{-1}$ at $7.5 \mathrm{~m}$ away from the main structure of the AAOT. The $L_{\mathrm{u}}, E_{\mathrm{u}}$ and $E_{\mathrm{d}}$ optical sensors are mounted at approximately the same depth (see Zibordi et al., 2004a). The rigidity and stability of the rig is maintained through two taut wires anchored between the tower and the sea bottom. The immovability of the AAOT and the relatively low deployment speed ensure an accurate optical characterization of the subsurface water layer.

WiSPER sensors include three OCI-200 for $E_{\mathrm{u}}(z, \lambda, t)$, $E_{\mathrm{d}}(z, \lambda, t)$ and $E_{\mathrm{d}}\left(0^{+}, \lambda, t\right)$, and one OCR-200 for $L_{\mathrm{u}}(z, \lambda, t)$ measurements. These sensors, manufactured by Satlantic Inc. (Halifax, Canada), provide data at $6 \mathrm{~Hz}$ in seven spectral bands $10 \mathrm{~nm}$ wide centered at 412, 443, 490, 510, 555, 665 and $683 \mathrm{~nm}$. The $L_{\mathrm{u}}$ sensor has approximately $18^{\circ}$ in-water full-angle field of view (FAFOV). Each WiSPER measurement sequence includes data from down- and up-casts.

WiSPER data are processed in agreement with the scheme presented in Sect. 3.1. Radiometric products for ARC intercomparison have been determined choosing an extrapolation interval of $0.3-3.0 \mathrm{~m}$. Additional processing includes the application of corrections for superstructure perturbations (Doyle and Zibordi, 2002), self-shading of $L_{\mathrm{u}}$ and $E_{\mathrm{u}}$ sensors (Gordon and Ding, 1992; Zibordi and Ferrari, 1995; Mueller et al., 2002), and non-cosine response of the abovewater $E_{\mathrm{d}}$ sensor (Zibordi and Bulgarelli, 2007). In addition to the diameter of the sensors, the application of these corrections requires spectral values of the above-water diffuse to direct irradiance ratio $(r)$, and subsurface seawater absorption $(a)$ and beam-attenuation $(c)$ coefficients (all regularly measured during each WiSPER deployment). 
Table 2. Summary of ARC systems/methods details and of main input quantities required for data processing (symbols $r, a$ and $c$ indicate the above-water diffuse to direct irradiance ratio, the seawater absorption and beam attenuation coefficients, respectively).

\begin{tabular}{|c|c|c|c|c|}
\hline System/method code & $\begin{array}{l}\text { Measurement type } \\
\text { (radiance) }\end{array}$ & $\begin{array}{l}\text { FAFOV } \\
\text { (radiance sensors) }\end{array}$ & $\begin{array}{l}\text { Acquisition frequency and } \\
\text { sampling time }\end{array}$ & Main input quantities \\
\hline WiSPER & $\begin{array}{l}\text { In-water manned continu- } \\
\text { ous profiles of multispec- } \\
\text { tral data in the } 400-700 \mathrm{~nm} \\
\text { spectral region with } 10 \mathrm{~nm} \\
\text { resolution }\end{array}$ & $18^{\circ}$ (in water) & $6 \mathrm{~Hz}, 160 \mathrm{~ms}$ & $\begin{array}{l}L_{\mathrm{u}}(z, \lambda, t), \\
E_{\mathrm{d}}\left(0^{+}, \lambda, t\right) \\
a(\lambda), c(\lambda), r(\lambda)\end{array}$ \\
\hline TACCS-S & $\begin{array}{l}\text { In-water autonomous fixed- } \\
\text { depth multispectral data in } \\
\text { the } 400-700 \mathrm{~nm} \text { spectral re- } \\
\text { gion with } 10 \mathrm{~nm} \text { resolution }\end{array}$ & $20^{\circ}$ (in water) & $\begin{array}{l}1 \mathrm{~Hz}, 15 \mathrm{~ms} \\
\text { (with } 1 \mathrm{~Hz} \text { low-pass filter) }\end{array}$ & $\begin{array}{l}L_{\mathrm{u}}\left(z_{i}, \lambda, t\right) \\
E_{\mathrm{d}}\left(z_{i}, \lambda, t\right) \\
E_{\mathrm{d}}\left(0^{+}, \lambda, t\right) \\
a(\lambda), c(\lambda)\end{array}$ \\
\hline TACCS-P & $\begin{array}{l}\text { In-water autonomous fixed- } \\
\text { depth hyperspectral data in } \\
\text { the } 350-800 \mathrm{~nm} \text { spectral re- } \\
\text { gion with } 11 \mathrm{~nm} \text { resolution }\end{array}$ & $18^{\circ}$ (in water) & $\begin{array}{l}2 \mathrm{~Hz}, 500 \mathrm{~ms} \\
\text { (typical for } L_{\mathrm{u}}\left(z_{i}, \lambda, t\right) \text { ) }\end{array}$ & $\begin{array}{l}L_{\mathrm{u}}\left(z_{i}, \lambda, t\right) \\
E_{\mathrm{d}}\left(z_{i}, \lambda, t\right) \\
E_{\mathrm{d}}\left(0^{+}, \lambda, t\right) \\
a(\lambda), c(\lambda), r(\lambda)\end{array}$ \\
\hline SeaPRISM & $\begin{array}{l}\text { Above-water autonomous } \\
\text { multispectral data in the } \\
400-1020 \mathrm{~nm} \text { spectral re- } \\
\text { gion with } 10 \mathrm{~nm} \text { resolution }\end{array}$ & $1.2^{\circ}$ (in air) & $\begin{array}{l}1 \mathrm{~Hz}, 200 \mathrm{~ms} \\
\text { (spectrally asynchronous) }\end{array}$ & $\begin{array}{l}L_{\mathrm{T}}(\theta, \Delta \phi, \lambda) \\
L_{i}\left(\theta^{\prime}, \Delta \phi, \lambda\right) \\
\left.E_{\mathrm{S}}\left(\theta_{0}, \phi_{0}, \lambda\right)\right) \\
W, \operatorname{Chl} a, \tau_{\mathrm{a}}(\lambda)\end{array}$ \\
\hline TRIOS-B & $\begin{array}{l}\text { Above-water manned hy- } \\
\text { perspectral data in the } 400- \\
900 \mathrm{~nm} \text { spectral region with } \\
10 \mathrm{~nm} \text { resolution }\end{array}$ & $7^{\circ}$ (in air) & $\begin{array}{l}0.1 \mathrm{~Hz}, 250 \mathrm{~ms} \\
\text { (typical for } L_{\mathrm{T}}(\theta, \Delta \phi, \lambda) \\
\text { during ARC) }\end{array}$ & $\begin{array}{l}L_{\mathrm{T}}(\theta, \Delta \phi, \lambda) \\
L_{i}\left(\theta^{\prime}, \Delta \phi, \lambda\right) \\
E_{\mathrm{d}}\left(0^{+}, \lambda, t\right) \\
W, \text { Chl } a\end{array}$ \\
\hline TRIOS-E & $\begin{array}{l}\text { Above-water manned hy- } \\
\text { perspectral data in the } 400- \\
900 \mathrm{~nm} \text { spectral region with } \\
10 \mathrm{~nm} \text { resolution }\end{array}$ & $7^{\circ}$ (in air) & $\begin{array}{l}0.1 \mathrm{~Hz}, 250 \mathrm{~ms} \\
\text { (typical for } L_{\mathrm{T}}(\theta, \Delta \phi, \lambda) \\
\text { during ARC) }\end{array}$ & $\begin{array}{l}L_{\mathrm{T}}(\theta, \Delta \phi, \lambda) \\
L_{i}\left(\theta^{\prime}, \Delta \phi, \lambda\right) \\
E_{\mathrm{d}}\left(0^{+}, \lambda, t\right) \\
W, \operatorname{Chl} a\end{array}$ \\
\hline
\end{tabular}

An analysis of uncertainties of WiSPER $R_{\mathrm{rS}}(\lambda)$ from ARC measurements, performed assuming each contribution independent from the others, indicates values in the range of approximately $4-5 \%$ in the selected spectral region (see Table 3). The uncertainty sources considered here are (i) uncertainty of the absolute radiance calibration (Hooker et al., $2002 \mathrm{~b}$ ) and immersion factor (Zibordi, 2006) for the $L_{\mathrm{u}}$ sensor (i.e. $2.7 \%$ and $0.5 \%$, respectively, composed statistically); (ii) uncertainty of the correction factors applied for removing self-shading and tower-shading perturbations computed as $25 \%$ of the applied corrections; (iii) uncertainty of the absolute irradiance calibration of the above-water $E_{\mathrm{d}}$ sensor (Hooker et al., 2002b) and uncertainties of the correction applied for the non-cosine response of the related irradiance collectors (Zibordi and Bulgarelli, 2007) (i.e. $2.3 \%$ and $1 \%$, respectively, composed statistically); (iv) uncertainty in the extrapolation of sub-surface values due to wave perturbations and changes in illumination and seawater optical properties during profiling cumulatively quantified as the average of the variation coefficient of $R_{\mathrm{rs}}(\lambda)$ from replicate measurements.

It is noted that the proposed uncertainty analysis accounts for fully independent calibrations of $E_{\mathrm{d}}$ and $L_{\mathrm{u}}$ sensors (i.e.
Table 3. Uncertainty budget (in percent) for $R_{\mathrm{rs}}$ determined from WiSPER data.

\begin{tabular}{lccc}
\hline Uncertainty source & 443 & 555 & 665 \\
\hline Absolute calibration of $L_{\mathrm{u}}(z, \lambda, t)$ & 2.8 & 2.8 & 2.8 \\
Self- and tower-shading corrections & 3.0 & 1.8 & 3.2 \\
Absolute calibration of $E_{\mathrm{d}}\left(0^{+}, \lambda, t\right)$ & 2.5 & 2.5 & 2.5 \\
Environmental perturbations & 0.7 & 0.7 & 0.8 \\
Quadrature sum & 4.9 & 4.2 & 5.0 \\
\hline
\end{tabular}

as obtained with different lamps and laboratory set-ups). The use of the same calibration lamp and set-up leads to a reduction of approximately $1 \%$ of the quadrature sum of spectral uncertainties for WiSPER $R_{\mathrm{rs}}(\lambda)$.

It is additionally noted that the bottom effects were not included in the uncertainty analysis being assumed to be negligible for the measuring conditions characterizing the ARC inter-comparison. In fact, despite the shallow water depth at the AAOT (i.e. $17 \mathrm{~m}$ ), an evaluation of bottom perturbations based on the scheme proposed by Zibordi et al. (2002a) 
indicates maximum values smaller than $0.5 \%$ for $R_{\mathrm{rs}}$ at the $555 \mathrm{~nm}$ center-wavelength.

The quality of WiSPER radiometric products is traced through quality-indices determined during data processing. These include (i) temporal changes in illumination conditions as caused by cloudiness and quantified through the standard deviation of $E_{\mathrm{d}}\left(0^{+}, \lambda, t\right)$ at each $\lambda$; (ii) potential difficulties in the determination of subsurface extrapolated quantities flagged by a relatively small number of measurements per unit depth, significant differences between $E_{\mathrm{u}}\left(z, \lambda, t_{0}\right) / L_{\mathrm{u}}\left(z, \lambda, t_{0}\right)$ at different depths in the extrapolation interval, and large differences between $E_{\mathrm{d}}\left(0^{-}, \lambda, t_{0}\right)$ and $E_{\mathrm{d}}\left(0^{+}, \lambda, t_{0}\right)$; and (iii) poor illumination conditions, resulting from high sun zenith angles or cloudiness, both quantified through values of the diffuse to direct irradiance ratio $r(\lambda)$ exceeding a threshold. These quality-indices, recorded as an integral part of the radiometric data set, are used to comprehensively qualify data products. The low deployment speed of WiSPER and the almost ideal sky and sea state conditions characterizing the ARC measurements made all the collected data applicable for the inter-comparison.

\subsubsection{TACCS}

The Tethered Attenuation Chain Colour Sensors (TACCS) manufactured by Satlantic Inc. consist of an above-water $E_{\mathrm{d}}$ sensor mounted on a buoy, an $L_{\mathrm{u}}$ upwelling radiance sensor at depth $z_{0}=0.5 \mathrm{~m}$, and a chain of four in-water $E_{\mathrm{d}}$ sensors at increasing depths $z_{\mathrm{i}}$. A weight suspended at the bottom of the chain stabilises the system against wave action. TACCS offers the advantage of easy deployment from small boats and the possibility of being operated at distances minimizing ship perturbations. Additionally, $L_{\mathrm{u}}\left(z_{0}, \lambda, t\right)$ data taken relatively close to the surface can be averaged over time to minimize the effects of wave focussing and defocusing. The main disadvantage is the reduced depth resolution with respect to profilers, requiring a careful quality check of data to exclude cases affected by near-surface vertical non-homogeneities.

Individual measurement sequences comprise collection of $L_{\mathrm{u}}\left(z_{0}, \lambda, t\right), E_{\mathrm{d}}\left(z_{\mathrm{i}}, \lambda, t\right)$ and $E_{\mathrm{d}}\left(0^{+}, \lambda, t\right)$ during intervals of three minutes. Measurement sequences are retained and corrected using Eq. (1) for the effects of illumination change during data collection when the variability of $E_{\mathrm{d}}\left(0^{+}, \lambda, t\right)$ is no greater than $2.5 \%$ with sea state $0-1,3.0 \%$ with sea state $1-2$, or $4 \%$ with sea state 4 (essentially, the variability should be consistent with wave action rather than with changes in illumination which have a higher frequency). Derived $L_{\mathrm{u}}\left(z_{0}, \lambda, t_{0}\right)$ and $E_{\mathrm{d}}\left(z_{\mathrm{i}}, \lambda, t_{0}\right)$ are then averaged over the three minute interval to determine time-averaged $\bar{L}_{\mathrm{u}}\left(z_{0}, \lambda, t_{0}\right)$ and $\bar{E}_{\mathrm{d}}\left(z_{\mathrm{i}}, \lambda, t_{0}\right)$, respectively.

Log transformed $\bar{E}_{\mathrm{d}}\left(z_{\mathrm{i}}, \lambda, t_{0}\right)$ are then applied to compute $K_{\mathrm{d}}(\lambda)$ through least-squares linear regressions. Because of the similarity of $K_{1}(\lambda)$ and $K_{\mathrm{d}}(\lambda)$ values (Mobley, 1994), subsurface $L_{\mathrm{u}}\left(0^{-}, \lambda\right)$ is then obtained from:

$L_{\mathrm{u}}\left(0^{-}, \lambda\right)=\frac{\bar{L}_{\mathrm{u}}\left(z_{0}, \lambda, t_{0}\right)}{e^{-z_{0} K_{\mathrm{d}}(\lambda)}}$.

Quality checks for $L_{\mathrm{u}}\left(0^{-}, \lambda\right)$ include the evaluation of $R^{2}$ determined from the regression of $\bar{E}_{\mathrm{d}}\left(z_{\mathrm{i}}, \lambda, t_{0}\right)$ at depths $z_{\mathrm{i}}$ and the visual inspection of $\bar{E}_{\mathrm{d}}\left(z_{\mathrm{i}}, 490, t_{0}\right)$ profile data. If $R^{2}$ and the vertical profile of log-transformed $\bar{E}_{\mathrm{d}}\left(z_{\mathrm{i}}, 490, t_{0}\right)$ indicate non-homogeneity of the optical properties in the water column, then the lowest depth(s) are removed from the processing. These steps aim to ensure the validity of the hypothesis of homogeneous seawater optical properties between the surface and at least the second measurement depth.

Self-shading corrections of $L_{\mathrm{u}}\left(0^{-}, \lambda\right)$ data are performed following the methodology detailed by Mueller et al. (2002). Input quantities are (i) the total seawater absorption coefficient $a(\lambda)$, on a first approximation assumed equal to $K_{\mathrm{d}}(\lambda)$ (Mobley, 1994) directly determined from $E_{\mathrm{d}}\left(z_{\mathrm{i}}, \lambda, t\right)$ values; (ii) the diameter of the $L_{\mathrm{u}}$ sensor (by neglecting the marginal effects of the surface float (Moore et al., 2010)); and (iii) the diffuse to direct irradiance ratio $r(\lambda)$ calculated from simulated data using the model of Bird and Riordan (1986) with extra-atmospheric sun irradiance from Thuillier et al. (2003) and aerosol optical thickness $\tau_{\mathrm{a}}(\lambda)$ from collocated sun-photometric measurements. Comparison of selfshading corrections determined for ARC measurement conditions with the former 2-D scheme (where the system is assumed a disk with diameter equal to the case of the $L_{\mathrm{u}}$ sensor) and corrections from a 3-D scheme developed by Leathers et al. (2001) for an equivalent buoy system indicates differences well within the $35 \%$ uncertainty declared for the 2-D based scheme (see the following subsections).

Two TACCS systems were deployed during the ARC intercomparison: one owned and managed by Stockholm University in collaboration with Bio-Optika (identified as TACCS$\mathrm{S}$ ), and the second by Sagremarisco Lda also in collaboration with Bio-Optika (identified as TACCS-P). Although the two TACCS systems have different radiometric configurations, the mechanical design is almost identical.

During the ARC activities both TACCS were operated at a few meters from each other at approximately $30 \mathrm{~m}$ from the AAOT.

\section{TACCS-S}

TACCS-S measures $E_{\mathrm{d}}\left(0^{+}, \lambda, t\right)$ at 443,490 and $670 \mathrm{~nm}$, and $E_{\mathrm{d}}\left(z_{\mathrm{i}}, \lambda, t\right)$ at $490 \mathrm{~nm}$ at the nominal depths of 2, 4, 6 and $8 \mathrm{~m}$. Measurements of $L_{\mathrm{u}}\left(z_{0}, \lambda, t\right)$ are performed at 412 , $443,490,510,560,620$ and $670 \mathrm{~nm}$ at the nominal depth $z_{0}=0.5 \mathrm{~m}$ with an in water FAFOV of approximately $20^{\circ}$. All sensors have a $10 \mathrm{~nm}$ bandwidth. The acquisition rate is approximately $1 \mathrm{~Hz}$.

TACCS-S does not have tilt sensors, but when carefully balanced in water, combined x-y tilt of the above-water $E_{\mathrm{d}}$ sensor remains below $5^{\circ}$ at sea state $0-1$. 
Table 4. Uncertainty budget (in percent) for $R_{\mathrm{rs}}$ determined from TACCS-S data.

\begin{tabular}{lccc}
\hline Uncertainty source & 443 & 560 & 670 \\
\hline Absolute calibration of $L_{\mathrm{u}}\left(z_{0}, \lambda, t\right)$ & 2.8 & 2.8 & 2.8 \\
Self-shading correction & 1.2 & 1.5 & 4.3 \\
Absolute calibration of $E_{\mathrm{d}}\left(0^{+}, \lambda, t\right)$ & 3.1 & 3.1 & 3.1 \\
Interpolation of missing $E_{\mathrm{d}}\left(0^{+}, \lambda, t\right)$ & 0.0 & 2.0 & 0.0 \\
Bio-Optical assumptions & 2.2 & 2.3 & 3.7 \\
Geometrical effects & 4.5 & 4.0 & 3.0 \\
Environmental perturbations & 1.1 & 1.1 & 1.9 \\
Quadrature sum & 6.7 & 6.8 & 7.9 \\
\hline
\end{tabular}

Since $E_{\mathrm{d}}\left(0^{+}, \lambda, t\right)$ is only measured at 443,490 and $670 \mathrm{~nm}$, simulated irradiances (computed using the same model utilized for the determination of $r$ ) are normalized to the actual $E_{\mathrm{d}}\left(0^{+}, \lambda, t\right)$ to determine values at $412,510,560$ and $620 \mathrm{~nm}$.

Similarly, since $K_{\mathrm{d}}(\lambda)$ is only measured at $490 \mathrm{~nm}$, spectral values of $K_{\mathrm{d}}(\lambda)$ at the relevant center-wavelengths are determined from measurements of $a(\lambda)$ and $c(\lambda)$ performed with an AC-9 (WET Labs, Philomath, USA) following Kirk (1994) with:

$K_{\mathrm{d}}(\lambda)=\mu_{0}^{-1}\left[a(\lambda)^{2}+\left(g_{1} \mu_{0}-g_{2}\right) a(\lambda) b(\lambda)\right]^{0.5}$,

where $b(\lambda)=c(\lambda)-a(\lambda), \mu_{0}$ is the mean cosine of the refracted solar beam just below the sea surface, and $g_{1}$ and $g_{2}$ constants depend on the scattering phase function. For the processing of ARC data, constant values are $\mu_{0}=0.86, g_{1}=$ 0.425 , and $g_{2}=0.19$ corresponding to the Petzold (1972) phase function. It is assumed that these parameters provide the correct spectral shape of $K_{\mathrm{d}}(\lambda)$, although its absolute value may be biased due to dependence of $\mu_{0}$ on $\theta_{0}$.

The analysis of uncertainties for TACCS-S $R_{\mathrm{rS}}(\lambda)$ from ARC measurements indicates values in the range of approximately 7-8\% (see Table 4). Considered uncertainty sources are (i) uncertainty of the absolute radiance calibration and immersion factor, computed as for WiSPER; (ii) uncertainty of the correction factors applied for removing self-shading perturbations in $L_{\mathrm{u}}\left(0^{-}, \lambda\right)$ computed as $35 \%$ of the applied corrections (the higher expected values with respect to WiSPER are explained by the assumption of $a(\lambda)=K_{\mathrm{d}}(\lambda)$ ); (iii) uncertainty of the absolute irradiance calibration of the above-water $E_{\mathrm{d}}$ sensor (Hooker et al., 2002b) and non-cosine response of the related irradiance collectors (Zibordi and Bulgarelli, 2007) (i.e. $2.3 \%$ and $2 \%$, respectively, composed statistically); (iv) uncertainty in the determination of $E_{\mathrm{d}}\left(0^{+}, \lambda, t\right)$ at missing center-wavelengths estimated by calculating $E_{\mathrm{d}}\left(0^{+}, \lambda, t\right)$ using the model of Bird and Riordan (1986) with $\tau_{\mathrm{a}}(500)=0.45$ (average for measurements performed during the field activities) and by bracketing the Ångström exponent at 0.0 and 2.0; (v) uncertainties due to the assumption of $K_{1}(\lambda)=K_{\mathrm{d}}(\lambda)$ resulting from the quadrature sum of $1.7 \%$, average difference between $K_{\mathrm{d}}(\lambda)$ and
$K_{1}(\lambda)$ determined through Hydrolight (Mobley, 1998) simulations using the specific TACCS $E_{\mathrm{d}}$ sensor depths, and of approximately $1.7 \%$ per $100 \mathrm{~nm}$ due to spectral extrapolation as estimated from actual measurements; (vi) uncertainties due to geometrical effects estimated from simulations, assuming tilt of $5^{\circ}$ for the above-water $E_{\mathrm{d}}$ sensor, relative sun-sensor azimuth of $180^{\circ}, \theta_{0}=45^{\circ}, r(\lambda)$ computed with $\tau_{\mathrm{a}}(500)=0.45$ and Ångström exponent equal to 1.39 as resulting from measurements performed during field activities; and (vii) uncertainty in the extrapolation of sub-surface values, computed as for WiSPER.

Uncertainties do not take into account potential shading of the in-water $E_{\mathrm{d}}$ sensors by the cable. This is supported by the assumption that this perturbation similarly affects measurements at all depths and thus does not significantly influence the determination of $K_{\mathrm{d}}(\lambda)$. No uncertainty has been assigned to the nominal depths of in-water $E_{\mathrm{d}}$ sensors assumed to be within $\pm 2 \mathrm{~cm}$ under calm sea.

Finally, in view of the inter-comparison analysis, it is anticipated that differences between TACCS-S centerwavelengths at 560 and $670 \mathrm{~nm}$ with respect to the reference ones at 555 and $665 \mathrm{~nm}$ are neglected.

\section{TACCS-P}

TACCS-P has hyperspectral sensors for $E_{\mathrm{d}}\left(0^{+}, \lambda, t\right)$ and $L_{\mathrm{u}}\left(z_{0}, \lambda, t\right)$ measurements with spectral range of 350 $800 \mathrm{~nm}$ and resolution of $11 \mathrm{~nm}$. The $L_{\mathrm{u}}$ sensor has in-water FAFOV of approximately $18^{\circ} . E_{\mathrm{d}}\left(z_{\mathrm{i}}, \lambda, t\right)$ is measured at $412,490,560$ and $665 \mathrm{~nm}$ with a bandwidth of $10 \mathrm{~nm}$ at nominal depths of $2,4,8$ and $16 \mathrm{~m}$. Sampling rate is typically $2 \mathrm{~Hz}$, although it may vary depending on illumination conditions. Tilt and compass sensors provide information on the levelling and orientation of the radiometer utilized for $E_{\mathrm{d}}\left(0^{+}, \lambda, t\right)$ measurements.

Since $K_{\mathrm{d}}(\lambda)$ is only determined at $412,490,560$ and $665 \mathrm{~nm}$, at the other relevant center-wavelengths it is determined with the following scheme. The value of Chl $a$ is estimated from $K_{\mathrm{d}}(490)$ by inverting Eq. (9) from Morel and Antoine (1994), duly taking into account the diffuse attenuation coefficient of pure seawater. Then the same equation with the estimated Chl $a$ is applied to determine the diffuse attenuation coefficient of seawater (pure seawater excluded). The derived $K_{\mathrm{d}}(\lambda)$ spectrum is subsequently normalised to the experimental values determined at 412, 490, 560 and $665 \mathrm{~nm}$.

$E_{\mathrm{d}}\left(0^{+}, \lambda, t\right)$ is calculated by two methods depending on tilt values during the sampling period. The value of $E_{\mathrm{d}}\left(0^{+}, \lambda, t\right)$ is kept unchanged if the combined $x-y$ tilt value is less than $2^{\circ}$. Otherwise a correction is applied by assuming that the diffuse irradiance is unaffected by tilt (i.e. by ignoring the sky radiance distribution) according to:

$E_{\mathrm{d}}\left(0^{-}, \lambda, t\right)=\frac{E_{\mathrm{d}}\left(0^{-}, \lambda, t, \theta_{\mathrm{s}}\right)}{1+\frac{f\left(\theta_{0}, \theta_{\mathrm{s}}\right)-1}{1+r(\lambda)}}$, 
Table 5. Uncertainty budget (in percent) for $R_{\mathrm{rs}}$ determined from TACCS-P data.

\begin{tabular}{lccc}
\hline Uncertainty source & 443 & 555 & 665 \\
\hline Absolute calibration of $L_{\mathrm{u}}\left(z_{0}, \lambda, t\right)$ & 2.8 & 2.8 & 2.8 \\
Self-shading corrections & 0.7 & 0.7 & 2.8 \\
Absolute calibration of $E_{\mathrm{d}}\left(0^{+}, \lambda, t\right)$ & 3.1 & 3.1 & 3.1 \\
Bio-Optical assumptions & 2.2 & 2.0 & 2.0 \\
Geometrical effects & 4.5 & 4.0 & 3.0 \\
Environmental perturbations & 1.8 & 1.9 & 3.9 \\
Quadrature sum & 6.8 & 6.4 & 7.3 \\
\hline
\end{tabular}

where $E_{\mathrm{d}}\left(0^{-}, \lambda, t, \theta_{\mathrm{s}}\right)$ indicates data uncorrected for tilt and $f\left(\theta_{0}, \theta_{\mathrm{S}}\right)$ is given by:

$f\left(\theta_{0}, \theta_{\mathrm{s}}\right)=\frac{\cos \left(\theta_{\mathrm{s}}\right)}{\cos \left(\theta_{0}\right)}$,

with $\theta_{\mathrm{s}}$ the apparent angle of the sun to the collector plane of the irradiance sensor.

This correction, however, only applies to tilts less than $8^{\circ}$ (chosen on the basis of trials performed under stable illumination conditions). In fact, when the tilt becomes high the radiance from the sea surface may add large perturbations, especially in the anti-solar direction.

The analysis of uncertainties for TACCS-P $R_{\mathrm{rS}}(\lambda)$ from ARC measurements indicates values in the range of approximately 6-7\% (see Table 5). Considered uncertainty sources are (i) uncertainty of the absolute radiance calibration and immersion factor of the $L_{\mathrm{u}}$ sensor, computed as for WiSPER; (ii) uncertainty in the correction factors applied for removing self-shading perturbations in $L_{\mathrm{u}}\left(z_{0}, \lambda, t\right)$, computed as for TACCS-S; (iii) uncertainty of the absolute irradiance calibration of the above-water $E_{\mathrm{d}}$ sensor and the non-cosine response of the related irradiance collectors, computed as for TACCS-S; (iv) uncertainties due to the assumption of $K_{\mathrm{l}}(\lambda)=K_{\mathrm{d}}(\lambda)$, computed as for TACCS-S; (v) uncertainties due to geometrical effects computed as for TACCS-S; and (vi) uncertainty due to the extrapolation of sub-surface values, computed as for WiSPER.

\subsubsection{SeaPRISM}

The SeaWiFS Photometer Revision for Incident Surface Measurements (SeaPRISM) is a modified CE-318 sun-photometer (CIMEL, Paris) that has the capability of performing autonomous above-water measurements. SeaPRISM is regularly operated at the AAOT from a deployment platform located in the western corner of the superstructure at approximately $15 \mathrm{~m}$ above the sea level (Zibordi et al., 2009c). Measurements performed with a FAFOV of $1.2^{\circ}$ every $30 \mathrm{~min}$ for the determination of $L_{\mathrm{W}}(\lambda)$ at a number of center-wavelengths including 412, 443, 488, 531, $551,670 \mathrm{~nm}$ (Zibordi et al., 2009c) are (i) the direct sun irradiance $E_{\mathrm{s}}\left(\theta_{0}, \phi_{0}, \lambda\right)$ acquired to determine the atmospheric optical thickness $\tau_{a}(\lambda)$ used for the theoretical computation of $E_{\mathrm{d}}\left(0^{+}, \lambda\right)$, and (ii) a sequence of 11 sea-radiance measurements for determining $L_{\mathrm{T}}(\theta, \Delta \phi, \lambda)$ and of 3 skyradiance measurements for determining $L_{\mathrm{i}}\left(\theta^{\prime}, \Delta \phi, \lambda\right)$. These sequences are serially repeated for each $\lambda$ with $\Delta \phi=90^{\circ}$, $\theta=40^{\circ}$ and $\theta^{\prime}=140^{\circ}$. The larger number of sea measurements, when compared to sky measurements, is required because of the higher environmental noise (mostly produced by wave perturbations) affecting the former measurements during clear sky.

Values of $R_{\mathrm{rS}}(\lambda)$ are determined from SeaPRISM measurements in agreement with basic principles provided in Sect. 3.2. An additional element is the need to minimize the effects of glint perturbations in $L_{\mathrm{T}}(\theta, \Delta \phi, \lambda)$ and possibly the effects of cloud perturbations in $L_{\mathrm{i}}\left(\theta^{\prime}, \Delta \phi, \lambda\right)$. This is achieved by deriving these values from the average of independent measurements satisfying strict filtering criteria ( $\mathrm{Zi}-$ bordi et al., 2009c; Zibordi, 2012).

Finally, as already anticipated, the value of $E_{\mathrm{d}}\left(0^{+}, \lambda\right)$ is quantified theoretically under the assumption of clear sky. Specifically,

$E_{\mathrm{d}}\left(0^{+}, \lambda\right)=E_{0}(\lambda) D^{2} t_{\mathrm{d}}(\lambda) \cos \theta_{0} \quad$,

where $D^{2}$ accounts for the variations in the Sun-Earth distance as a function of the day of the year (Iqbal, 1983), $t_{\mathrm{d}}(\lambda)$ is the atmospheric diffuse transmittance computed from measured values of $\tau_{\mathrm{a}}(\lambda)$ (Gordon and Clark, 1981), and $E_{0}(\lambda)$ is the average extra-atmospheric sun irradiance (Thuillier et al., 2003).

Quality flags are applied at the different processing levels to remove poor determinations of $R_{\mathrm{rs}}(\lambda)$. Quality flags include checking for (see Zibordi et al., 2009c) cloud contamination, high variance of multiple sea- and sky-radiance measurements, elevated differences between pre- and postdeployment calibrations of the SeaPRISM system, and spectral inconsistency of the normalized water-leaving radiance $L_{\mathrm{wn}}(\lambda)$ given by:

$L_{\mathrm{wn}}(\lambda)=R_{\mathrm{rs}}(\lambda) E_{0}(\lambda)$.

It is recalled that SeaPRISM data, handled through the Ocean Color component of the Aerosol Robotic Network (AERONET-OC, Zibordi et al., 2009c), are mostly intended to support satellite ocean color validation activities. Because of this, to minimize the effects of differences in centerwavelengths between the satellite and SeaPRISM data products a band-shift correction scheme has been developed for the latter. These corrections are performed relying on a biooptical model requiring Chl $a$ and IOP values estimated through regional empirical algorithms applied to spectral ratios of $L_{\mathrm{wn}}(\lambda)$ (Zibordi et al., 2009b). Band-shift corrections have then been applied to SeaPRISM data products contributing to the ARC inter-comparison to match the reference center-wavelengths.

SeaPRISM is the only system deployed during the ARC experiment that was not immediately inter-calibrated. This 
Table 6. Uncertainty budget (in percent) for $R_{\mathrm{rs}}$ determined from SeaPRISM data.

\begin{tabular}{lccc}
\hline Uncertainty source & 443 & 555 & 665 \\
\hline Absolute calibration & 2.7 & 2.7 & 2.7 \\
Viewing angle correction & 2.2 & 2.0 & 2.2 \\
Uncertainties in $t_{\mathrm{d}}(\lambda), \rho(\theta), W$ & 2.1 & 1.7 & 2.9 \\
Uncertainties in $E_{0}(\lambda)$ & 1.6 & 0.7 & 0.1 \\
Environmental perturbations & 2.0 & 1.9 & 8.7 \\
Quadrature sum & 4.5 & 4.2 & 9.8 \\
\hline
\end{tabular}

is justified by its continuous operation for periods of 6-12 months at the AAOT. However, pre- and post-deployment calibrations performed at the JRC with the same standards and methods applied during ARC indicated differences typically within $0.6 \%$ during a 9 month period.

Estimated uncertainties of SeaPRISM $R_{\mathrm{rS}}(\lambda)$ data for the ARC experiment are approximately $4-5 \%$ in the blue-green spectral regions and $10 \%$ in the red (see Table 6). These have been determined accounting for contributions from (i) uncertainty of the absolute radiance calibration (Hooker et al., 2002b) for $L_{\mathrm{T}}$ and $L_{\mathrm{i}}$ sensors, but neglecting sensitivity changes during deployment which should contribute less than $0.2 \%$ when assuming a linear change with time between pre- and post-deployment calibrations; (ii) uncertainty of corrections for the off-nadir viewing geometry computed as $25 \%$ of the applied correction factors (these relatively large percent values are expected to account for uncertainties due to the intrinsic assumption of Case 1 water at the AAOT); (iii) variability in specific parameters required for the determination of $R_{\mathrm{rs}}(\lambda)$ (taken from Zibordi et al., 2009c, and estimated from multi-annual measurements accounting for changes in wind speed, sea surface reflectance, and atmospheric diffuse transmittance); (iv) uncertainty in $E_{0}(\lambda)$ estimated by assuming $\pm 1 \mathrm{~nm}$ uncertainty in center-wavelengths; and finally, (v) environmental perturbations (e.g. wave effects, changes in illumination and seawater optical properties during measurements) quantified as the average of the variation coefficient obtained from $R_{\mathrm{rS}}(\lambda)$ values from replicate measurements.

The uncertainty related to band-shift corrections has not been accounted for in the overall budget. However, an evaluation of band-shift corrections applied to SeaPRISM data to match center-wavelengths of various satellite sensors indicated average values of a few percent (Zibordi et al., 2006). Thus, the uncertainty affecting these values is expected to be a small fraction of the applied corrections and consequently to not significantly impact the uncertainty budget proposed for SeaPRISM $R_{\mathrm{rs}}(\lambda)$.

\subsubsection{TRIOS}

Above-water TriOS (Rastede, Germany) Optical Systems (TRIOS) are composed of two RAMSES ARC-
VIS hyperspectral radiometers measuring $L_{\mathrm{T}}(\theta, \Delta \phi, \lambda)$ and $L_{\mathrm{i}}\left(\theta^{\prime}, \Delta \phi, \lambda\right)$, and one RAMSES ACC-VIS for $E_{\mathrm{d}}\left(0^{+}, \lambda\right)$. Measurements are performed in the $400-900 \mathrm{~nm}$ spectral range with resolution of about $10 \mathrm{~nm}$ for the output data. The nominal FAFOV of radiance sensors is $7^{\circ}$.

The basic measurement method applied during ARC is that developed by Ruddick et al. (2006, see the main paper and web appendices) based on the generic Method 1 described in the Ocean Optics Protocols (Mueller et al., 2002).

$L_{\mathrm{T}}$ and $L_{\mathrm{i}}$ sensors are simultaneously operated on the same frame with identical azimuth plane, and $\theta=40^{\circ}$ and $\theta^{\prime}=140^{\circ}$, respectively. Measurement sequences are performed with user-definable intervals and frequencies, and integration time varying automatically between $8 \mathrm{~ms}$ and $4 \mathrm{~s}$ depending on the brightness of the target. During ARC, the deployment frame was adjusted for each measurement sequence to satisfy the requirement of $\Delta \phi=135^{\circ}$ (or occasionally of $\Delta \phi=90^{\circ}$, chosen to avoid superstructure perturbations).

Details on data processing, including measurement selection, averaging and quality checks, are described in Ruddick et al. (2006) (web appendix 1: http://aslo.org/lo/toc/vol_51/ issue_2/1167a1.pdf). A few elements on data processing are however provided here for completeness.

Following Ruddick et al. (2006) and in agreement with Sects. 3.2 and 3.1 , the remote sensing reflectance $R_{\mathrm{rs}}^{\prime}(\theta, \Delta \phi, \lambda)$ for individual $L_{\mathrm{T}}(\theta, \Delta \phi, \lambda)$ and $L_{\mathrm{i}}\left(\theta^{\prime}, \Delta \phi, \lambda\right)$ measurements is computed as:

$R_{\mathrm{rs}}^{\prime}(\theta, \Delta \phi, \lambda)=\frac{L_{\mathrm{T}}(\theta, \Delta \phi, \lambda)-\rho^{\prime}(W) L_{\mathrm{i}}\left(\theta^{\prime}, \Delta \phi, \lambda\right)}{E_{\mathrm{d}}\left(0^{+}, \lambda\right)}$,

where $\rho^{\prime}(W)$ indicates the sea surface reflectance during clear sky conditions, solely expressed as a function of $W$ (in units of $\mathrm{ms}^{-1}$ ),

$\rho^{\prime}(W)=0.0256+0.00039 W+0.000034 W^{2}$.

Minimization of perturbations due to wave effects is then achieved through the so-called turbid water near-infrared (NIR) similarity correction (Ruddick et al., 2005) by determining the departure from the NIR similarity spectrum with:

$\varepsilon=\frac{\alpha \cdot R_{\mathrm{rs}}^{\prime}\left(\theta, \Delta \phi, \lambda_{2}\right)-R_{\mathrm{rs}}^{\prime}\left(\theta, \Delta \phi, \lambda_{1}\right)}{\alpha-1}$,

where wavelengths $\lambda_{1}$ and $\lambda_{2}$ are chosen in the near infrared and the constant $\alpha$ is set accordingly from Table 2 of Ruddick et al. (2006). It is noted that this scheme is similar to that proposed by Gould et al. (2001), although relying on different wavelengths and values of $\alpha$ and of the sea surface reflectance.

The NIR similarity corrected remote sensing reflectance $R_{\mathrm{rs}}(\theta, \Delta \phi, \lambda)$ is then calculated from:

$R_{\mathrm{rs}}(\theta, \Delta \phi, \lambda)=R_{\mathrm{rs}}^{\prime}(\theta, \Delta \phi, \lambda)-\varepsilon$, 
Table 7. Uncertainty budget (in percent) for $R_{\mathrm{rs}}$ determined from TRIOS-B data.

\begin{tabular}{lccc}
\hline Uncertainty source & 443 & 555 & 665 \\
\hline System calibration & 2.0 & 2.0 & 2.0 \\
Straylight effects & 5.0 & 0.5 & 1.0 \\
Polarization effects & 1.0 & 1.0 & 1.0 \\
Non-cosine response of $E_{\mathrm{d}}$ & 2.0 & 2.0 & 2.0 \\
Sky-light correction & 2.0 & 1.0 & 2.9 \\
Viewing angle correction & 1.5 & 1.5 & 1.5 \\
Quadrature sum & 6.3 & 3.5 & 4.5 \\
\hline
\end{tabular}

where the correction is assumed spectrally invariant. The corresponding NIR similarity corrected water-leaving radiance is calculated as:

$L_{\mathrm{w}}(\theta, \Delta \phi, \lambda)=E_{\mathrm{d}}\left(0^{+}, \lambda\right) R_{\mathrm{rs}}(\theta, \Delta \phi, \lambda)$.

A number of data products (i.e. 5) are then averaged to obtain the NIR similarity corrected $\bar{L}_{\mathrm{w}}(\theta, \Delta \phi, \lambda)$.

For ARC measurements a viewing angle correction is also applied to $\bar{L}_{\mathrm{W}}(\theta, \Delta \phi, \lambda)$ in agreement with Eq. (5) to determine $L_{\mathrm{W}}(\lambda)$. The values of Chl $a$ required for such a correction were estimated using a regional band-ratio algorithm (Berthon and Zibordi, 2004).

Two TRIOS systems were deployed at the AAOT adjacent to the SeaPRISM during the ARC experiment: one owned and handled by the Management Unit of the North Sea Mathematical Models (identified as TRIOS-B) and the other by Tartu Observatory (identified as TRIOS-E). The two systems are equivalent, but measurements have been performed independently and reduced by applying slightly different schemes, corresponding to the standard practices of the two institutions and with some differences in the approach for uncertainty estimate. These elements are separately presented in the following subsections.

Data for inter-comparisons have been constructed by linearly interpolating quality checked products at the reference center-wavelengths.

\section{TRIOS-B}

$E_{\mathrm{d}}\left(0^{+}, \lambda\right), L_{\mathrm{T}}(\theta, \Delta \phi, \lambda)$ and $L_{\mathrm{i}}\left(\theta^{\prime}, \Delta \phi, \lambda\right)$ are simultaneously acquired for $10 \mathrm{~min}$ taking measurements every $10 \mathrm{~s}$. Calibrated data are quality checked for incomplete and for individual measurements differing by more than $25 \%$ from the neighbouring ones. In the case of ARC data, quality checking led to the rejection of $1 \%$ of measurements. The NIR similarity correction is then performed using $\lambda_{1}=780 \mathrm{~nm}$, $\lambda_{2}=870 \mathrm{~nm}$, and $\alpha=1.91$ (Ruddick et al., 2006).

Estimated uncertainties of $R_{\mathrm{rs}}(\lambda)$ for TRIOS-B approximately vary between 4 and $6 \%$ in the spectral range of interest (see Table 7). The considered uncertainty sources are (i) uncertainty of system calibration determined assuming the same irradiance standard is utilized for the absolute cal-
Table 8. Uncertainty budget (in percent) for $R_{\mathrm{rs}}$ determined from TRIOS-E data.

\begin{tabular}{lccc}
\hline Uncertainty source & 443 & 555 & 665 \\
\hline System calibration & 2.0 & 2.0 & 2.0 \\
Straylight effects & 5.0 & 0.5 & 1.0 \\
Polarization effects & 1.0 & 1.0 & 1.0 \\
NIR similarity correction & 0.5 & 0.4 & 2.2 \\
Viewing angle correction & 1.5 & 1.7 & 1.3 \\
Non-cosine response of $E_{\mathrm{d}}$ & 2.0 & 2.0 & 2.0 \\
Environmental perturbations & 1.8 & 1.0 & 2.0 \\
Quadrature sum & 6.3 & 3.6 & 4.5 \\
\hline
\end{tabular}

ibration of the $E_{\mathrm{d}}, L_{\mathrm{T}}$, and $L_{\mathrm{i}}$ sensors, and thus only accounting for effects of mechanical setup, inadequate baffling and reference plaque uncertainties (see Hooker et al., 2002b); (ii) uncertainty due to straylight effects quantified through the application of laboratory characterizations performed for RAMSES $E_{\mathrm{d}}, L_{\mathrm{T}}$ and $L_{\mathrm{i}}$ sensors (Ansko, unpublished); (iii) polarization effects quantified as the maximum sensitivity to polarization determined through laboratory characterizations for RAMSES $L_{\mathrm{T}}$ and $L_{\mathrm{i}}$ sensors (Ruddick, unpublished); (iv) effects of non-cosine response of the above-water $E_{\mathrm{d}}$ collector determined from laboratory measurements (Ruddick, unpublished); (v) uncertainty in sky-light correction quantified in agreement with Ruddick et al. (2006) as a function of the uncertainty in $\rho^{\prime}(W)$; and (vi) uncertainty in the correction for off-nadir viewing angle quantified as $25 \%$ of the applied corrections, and exhibiting different values than those proposed for SeaPRISM because of the diverse viewing geometry generally relying on $\Delta \phi=135^{\circ}$ instead of $\Delta \phi=90^{\circ}$.

It is noted that the uncertainty for the sky glint correction is highly dependent on sea state, and the relative percent value of this uncertainty is inversely proportional to $R_{\mathrm{rs}}(\theta, \Delta \phi, \lambda)$ (see web appendix 2 of Ruddick et al., 2006). The values given here have, therefore, been calculated very specifically accounting for the sea state recorded during the ARC activities and the observed water-leaving radiances (see Sect. 4). Measurements performed in different waters or sea state conditions may lead to different uncertainties.

\section{TRIOS-E}

The $L_{\mathrm{T}}(\theta, \Delta \phi, \lambda), L_{\mathrm{i}}\left(\theta^{\prime}, \Delta \phi, \lambda\right)$, and $E_{\mathrm{d}}\left(0^{+}, \lambda\right)$ measurement sequences are simultaneously recorded every $10 \mathrm{sec}-$ onds for approximately $6 \mathrm{~min}$, commonly using $\Delta \phi=135^{\circ}$. The NIR similarity correction is performed with $\lambda_{1}=$ $720 \mathrm{~nm}, \lambda_{2}=780 \mathrm{~nm}$ and $\alpha=2.35$ (Ruddick et al., 2006). The rationale for choosing this wavelength pair, different from that applied for TRIOS-B, is the higher signal to noise ratio characterizing measurements at the shorter wavelengths. 


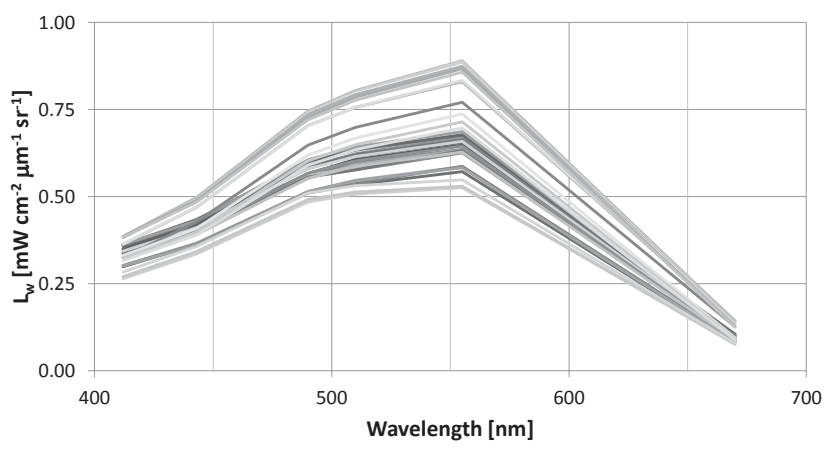

Fig. 1. $L_{\mathrm{W}}(\lambda)$ spectra from WiSPER produced during the ARC experiment at the AAOT.

Quality checks rely on the mode of $R_{\mathrm{rs}}(555)$ for each measurement sequence. Data deviating by more than $10 \%$ from the mode value are rejected; actually none of the clear sky data included in the ARC inter-comparison was discarded.

Estimated uncertainties of $R_{\mathrm{rS}}(\lambda)$ from TRIOS-E vary approximately within 4-6\% (see Table 8 ). The considered uncertainty sources are (i) uncertainty of system calibration, computed as for TRIOS-B; (ii) uncertainty due to straylight effects, computed as for TRIOS-B; (iii) polarization effects, computed as for TRIOS-B; (iv) uncertainty in the turbid water NIR similarity correction quantified accounting for $25 \%$ of the applied corrections; (v) uncertainty in the correction for off-nadir viewing angle (also estimated as $25 \%$ of the applied corrections); (vi) effects of non-cosine response of the $E_{\mathrm{d}}$ collector guessed from published data (Zibordi and Bulgarelli, 2007); and (vii) environmental perturbations estimated from the variation coefficient of $R_{\mathrm{rs}}(\lambda)$ from the same measurement sequence.

\section{Data analysis and results}

The inter-comparison analysis has been performed using matchups (i.e. pairs of data products from different systems) constructed by setting \pm 15 min maximum difference between measurements from the two systems/methods to be compared. Matchup analysis has been performed through the average of relative and of absolute values of percent differences. Specifically, the average of relative percent differences $(\mathrm{RD})$ is computed as:

$\mathrm{RD}=100 \frac{1}{N} \sum_{n=1}^{N} \frac{\Re^{C}(n)-\Re^{R}(n)}{\Re^{R}(n)}$,

while the average of absolute values of percent differences $(\mathrm{AD})$ is given by:

$\mathrm{AD}=100 \frac{1}{N} \sum_{n=1}^{N} \frac{\left|\mathfrak{R}^{C}(n)-\mathfrak{R}^{R}(n)\right|}{\mathfrak{R}^{R}(n)}$,
Table 9. Values of major quantities characterizing the measurement conditions during ARC activities at the AAOT.

\begin{tabular}{lcc}
\hline Quantity & Mean \pm Std & Range (min-max) \\
\hline$L_{\mathrm{W}}(490)\left[\mathrm{mW} \mathrm{cm}^{-2} \mu \mathrm{m}^{-1} \mathrm{sr}^{-1}\right]$ & $0.64 \pm 0.09$ & $0.51-0.81$ \\
$K_{\mathrm{d}}(490)\left[\mathrm{m}^{-1}\right]$ & $0.19 \pm 0.02$ & $0.16-0.22$ \\
$K_{1}(490)\left[\mathrm{m}^{-1}\right]$ & $0.20 \pm 0.02$ & $0.16-0.25$ \\
$a(490)\left[\mathrm{m}^{-1}\right]$ & $0.15 \pm 0.01$ & $0.13-0.16$ \\
$c(490)\left[\mathrm{m}^{-1}\right]$ & $1.20 \pm 0.07$ & $1.05-1.34$ \\
$a_{\mathrm{y}}(412)\left[\mathrm{m}^{-1}\right]$ & $0.17 \pm 0.03$ & $0.13-0.20$ \\
Chl $a\left[\mu \mathrm{g} \mathrm{l} l^{-1}\right]$ & $0.9 \pm 0.3$ & $0.6-1.5$ \\
$\mathrm{TSM}\left[\mathrm{mg} \mathrm{l}^{-1}\right]$ & $1.8 \pm 0.4$ & $1.3-2.4$ \\
$\mathrm{~W}[\mathrm{~m} \mathrm{~s}-1]$ & $2.9 \pm 1.1$ & $0.9-4.5$ \\
$\theta_{0}[$ degrees] & $30.3 \pm 5.2$ & $24.6-43.1$ \\
Cloud cover [octs] & $0 \pm 0$ & $0-0$ \\
\hline
\end{tabular}

where $N$ is the number of matchups, $n$ is the matchup index, superscript $C$ indicates the quantity to be compared, and superscript $R$ indicates the reference. While $\mathrm{RD}$ is applied as an index to measure biases, $\mathrm{AD}$ is applied to quantify scattering between compared values.

The root mean square of differences (RMS),

$\mathrm{RMS}=\sqrt{\frac{1}{N} \sum_{n=1}^{N}\left(\Re^{C}(n)-\Re^{R}(n)\right)^{2},}$

is also included in the analysis as a statistical index to quantify differences in absolute units.

Data products from WiSPER are applied as the reference. This choice is only supported by the confidence acquired with the system and the related measurement method. WiSPER data for ARC inter-comparisons comprise measurements from 36 independent casts performed under clear sky conditions from 21 to 24 July 2010. Derived $L_{\mathrm{w}}(\lambda)$ spectra are given in Fig. 1. The shape of spectra suggests a water type characterized by moderate concentrations of phytoplankton and colored dissolved organic matter, as shown by the decrease of spectra from $555 \mathrm{~nm}$ toward $412 \mathrm{~nm}$, and additionally, moderate concentration of total suspended matter, as shown by non-negligible values at $665 \mathrm{~nm}$. An evaluation of the water type made in agreement with Loisel and Morel (1998) indicates the presence of Case 2 water during the whole field experiment. Values for relevant quantities describing measurement conditions are reported in Table 9. Specifically, measurements performed on water samples collected during ARC activities at the AAOT indicate average Chl $a$ values of $0.9 \pm 0.3 \mu \mathrm{gl}^{-1}$, concentrations of total suspended matter (TSM) of $1.8 \pm 0.4 \mathrm{~g}^{-1}$, and absorption coefficient by colored dissolved organic matter $a_{y}$ at $412 \mathrm{~nm}$ of $0.17 \pm 0.03 \mathrm{~m}^{-1}$. However, despite the relative constancy of near surface quantities, the analysis of $a(\lambda)$ and $c(\lambda)$ profile data collected simultaneously to WiSPER measurements with an AC-9 showed occasionally marked optical stratifications at depths comprised between 5 and $13 \mathrm{~m}$. The 

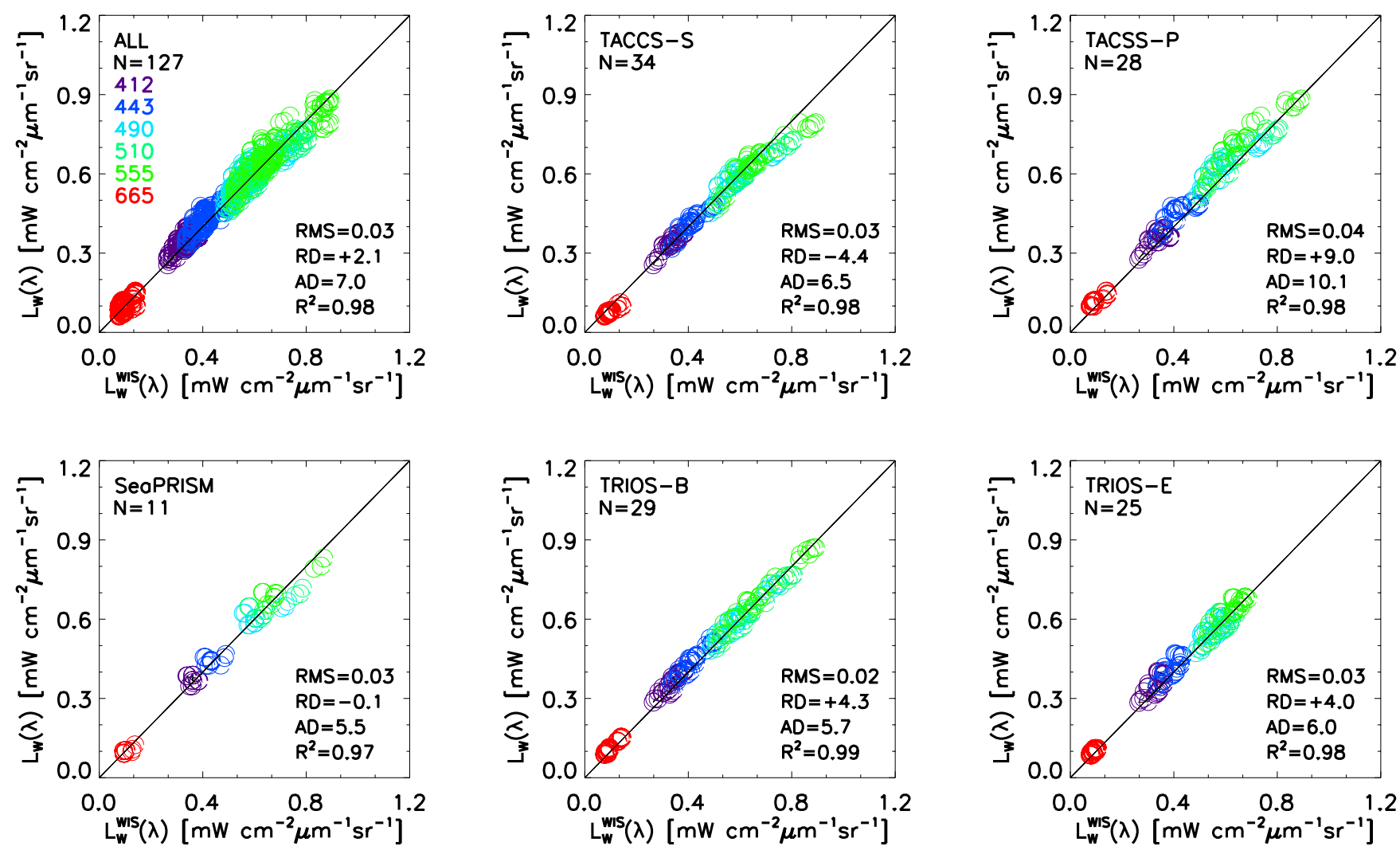

Fig. 2. Scatter plots of $L_{\mathrm{w}}(\lambda)$ from the various systems/methods versus $L_{\mathrm{W}}(\lambda)$ from WiSPER (ALL indicates merged data from all individual inter-comparisons). RMS indicates the spectrally averaged root mean square of relative differences, while RD and AD in \% indicate spectrally averaged values of relative differences and of absolute values of relative differences, respectively. $N$ is the number of matchups, all obtained assuming a \pm 15 min maximum difference between measurements. Diverse colors indicate data at different center-wavelengths.

exclusion from data processing of the measurements related to these depths has minimized potential inconsistencies in the inter-comparison of products likely affected by the nonlinear decay with depth of $\log$-transformed $L_{\mathrm{u}}\left(z, \lambda, t_{0}\right)$ and $E_{\mathrm{d}}\left(z, \lambda, t_{0}\right)$ data.

By recalling that the objective of the inter-comparison is the evaluation of the overall performance of different systems/methods regularly applied for satellite ocean color validation activities, and not a detailed investigation of any individual method, a summary of inter-comparison results is presented through scatter plots in Figs. 2-4 for $L_{\mathrm{w}}(\lambda), E_{\mathrm{d}}\left(0^{+}, \lambda\right)$ and $R_{\mathrm{rs}}(\lambda)$, respectively. The different number of matchups included in the analysis for the various systems/methods is explained by practical deployment issues for various systems on some days, such as the application of the \pm 15 min threshold not always being reached because of inadequate synchronization of the start of measurement sequences, or like in the case of SeaPRISM data, justified by the automatic and fully asynchronous (when compared to ARC activities) execution of measurements. It is however reported that most of the TRIOS-B and TRIOS-E measurements used to construct matchups are within \pm 1 min from WiSPER measure- ments, while most of TACCS-S and TACCS-P measurements are within \pm 3 min.

Inter-comparisons of $L_{\mathrm{w}}(\lambda)$ displayed in Fig. 2 exhibit values of RMS in the range of $0.02-0.03 \mathrm{~mW} \mathrm{~cm}^{-2} \mu \mathrm{m}^{-1} \mathrm{sr}^{-1}$, except TACCS-P reaching $0.04 \mathrm{~mW} \mathrm{~cm}^{-2} \mu \mathrm{m}^{-1} \mathrm{sr}^{-1}$. Spectrally averaged values of $\mathrm{RD}$ and $\mathrm{AD}$ are generally within $\pm 4 \%$ and $5-7 \%$, respectively. Higher values (i.e. +9 and $10 \%$ ) are observed for TACCS-P. Determination coefficients, $R^{2}$, exhibit values higher than 0.98 , except for the SeaPRISM data where $R^{2}=0.97$.

The inter-comparison results of $E_{\mathrm{d}}\left(0^{+}, \lambda\right)$, shown in Fig. 3, also exhibit quite good results when considering the variety of instruments and also methods applied. In particular, RMSs are close to $5 \mathrm{~mW} \mathrm{~cm}^{-2} \mu \mathrm{m}^{-1}$ for the above-water systems/methods and between 8 and $10 \mathrm{~mW} \mathrm{~cm}^{-2} \mu \mathrm{m}^{-1}$ for TACCS-S and TACCS-P, respectively. The different performances of TRIOS and TACCS systems are explained by the diverse deployment methods; TRIOS $E_{\mathrm{d}}\left(0^{+}, \lambda\right)$ measurements benefit from a fixed deployment platform while TACCS measurements are affected by the buoy motion adding geometric perturbations as a function of sea state. The RMS value determined for SeaPRISM is comparable to that obtained for TRIOS. This result acquires particular relevance 

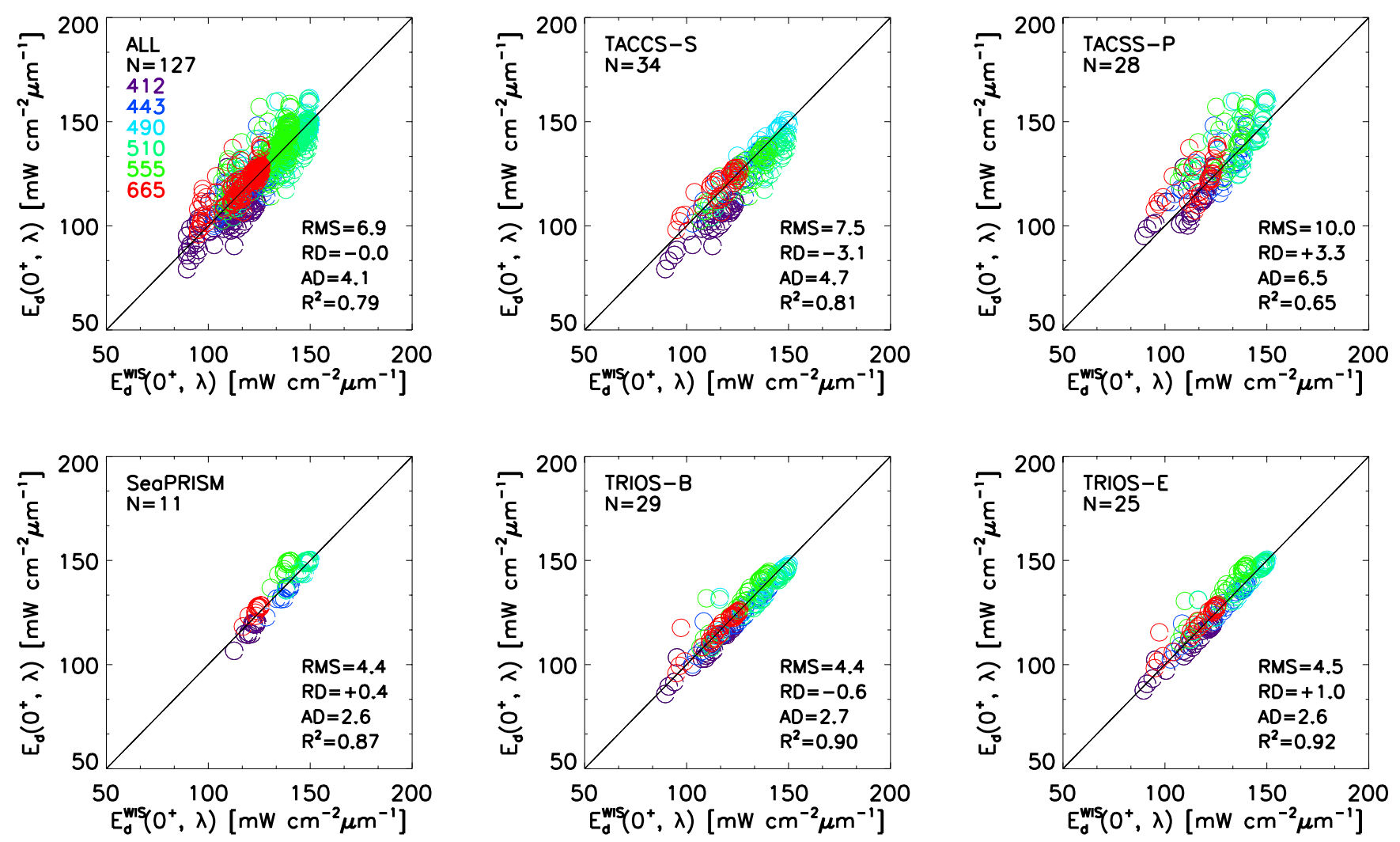

Fig. 3. As in Fig. 2 but for $E_{\mathrm{d}}\left(0^{+}, \lambda\right)$.

when considering that SeaPRISM $E_{\mathrm{d}}\left(0^{+}, \lambda\right)$ data are determined theoretically from experimental values of $\tau_{\mathrm{a}}(\lambda)$, a very different approach from actual measurements applied for all other systems/methods. Values of RD for $E_{\mathrm{d}}\left(0^{+}, \lambda\right)$ are approximately within $\pm 3 \%$ while values of $\mathrm{AD}$ are close to $3 \%$ for the above-water systems (e.g. SeaPRISM, TRIOS$\mathrm{B}$ and TRIOS-E), but reach 5-7\% for the buoy-based systems/methods (i.e. TACCS-S and TACCS-P). Similarly, $R^{2}$ vary between 0.87 and 0.92 for the above-water systems, and exhibit much lower values for TACCS-S and TACCS-P (i.e. $R^{2}$ equal to 0.81 and 0.65 , respectively).

The inter-comparison shown in Fig. 4 for $R_{\mathrm{rs}}(\lambda)$ data exhibits results obviously depending on those obtained for $L_{\mathrm{W}}(\lambda)$ and $E_{\mathrm{d}}\left(0^{+}, \lambda\right)$ data. Specifically, lower RMS values (i.e. $0.0002 \mathrm{sr}^{-1}$ ) are shown for TRIOS-B and TRIOS-E, and the highest (i.e. $0.0004 \mathrm{sr}^{-1}$ ) for TACCS-P. RD values vary from -1 to $+6 \%$, while $\mathrm{AD}$ values are approximately $6 \%$ for the above-water systems and reach $9 \%$ for the buoybased systems. All $R^{2}$ vary between 0.95 and 0.99 with the lowest values again displayed by the TACCS-S and TACCSP $R_{\mathrm{rS}}(\lambda)$ as a result of the lower $R^{2}$ shown by $E_{\mathrm{d}}\left(0^{+}, \lambda\right)$.

The former analysis efficiently summarizes the general performances of the various systems/methods, but limits the possibility of evaluating the spectral performances at the selected center-wavelengths. The inter-comparison analysis is then completed with the presentation of spectral statistical indices for each system/method in Tables $10-12$ for $L_{\mathrm{W}}(\lambda)$, $E_{\mathrm{d}}\left(0^{+}, \lambda\right)$ and $R_{\mathrm{rs}}(\lambda)$, respectively. These data show various peculiarities. For instance, $R^{2}$ determined from spectral values of $L_{\mathrm{W}}(\lambda)$ and $R_{\mathrm{rs}}(\lambda)$ are much lower than those computed with spectrally combined data (e.g. note the striking values for SeaPRISM $L_{\mathrm{w}}$ at $443 \mathrm{~nm}$ ). This is undoubtedly explained by the small range characterizing the spectral values of $L_{\mathrm{w}}(\lambda)$ due to the low variability of the seawater biooptical properties (see Table 9). When looking at Table 10, also relevant are the biases affecting TACCS-S and TACCS-P (i.e. $-20 \%$ and $+21 \%$, respectively) and also TRIOS-B and TRIOS-E (i.e. $+12 \%$ and $+10 \%$, respectively) at $665 \mathrm{~nm}$. These are likely explained by the difficulty in determining near surface $K_{\mathrm{d}}(665)$ for TACCS and by imperfect sky-glint removal for TRIOS.

The evaluation of $E_{\mathrm{d}}\left(0^{+}, \lambda\right)$ data shows the highest values of RMS, RD and AD for TACCS-P, which is likely explained by wave perturbations. Statistical results for $R_{\mathrm{rs}}(\lambda)$ reflect those already presented for $L_{\mathrm{W}}(\lambda)$ and $E_{\mathrm{d}}\left(0^{+}, \lambda\right)$, mainly indicating significant biases at $665 \mathrm{~nm}$ for most of the considered methods/systems. An investigation of reasons for the observed differences is, however, beyond the scope of the work and likely out of the capabilities offered by the relatively small ARC data set tied to specific measurement conditions. 

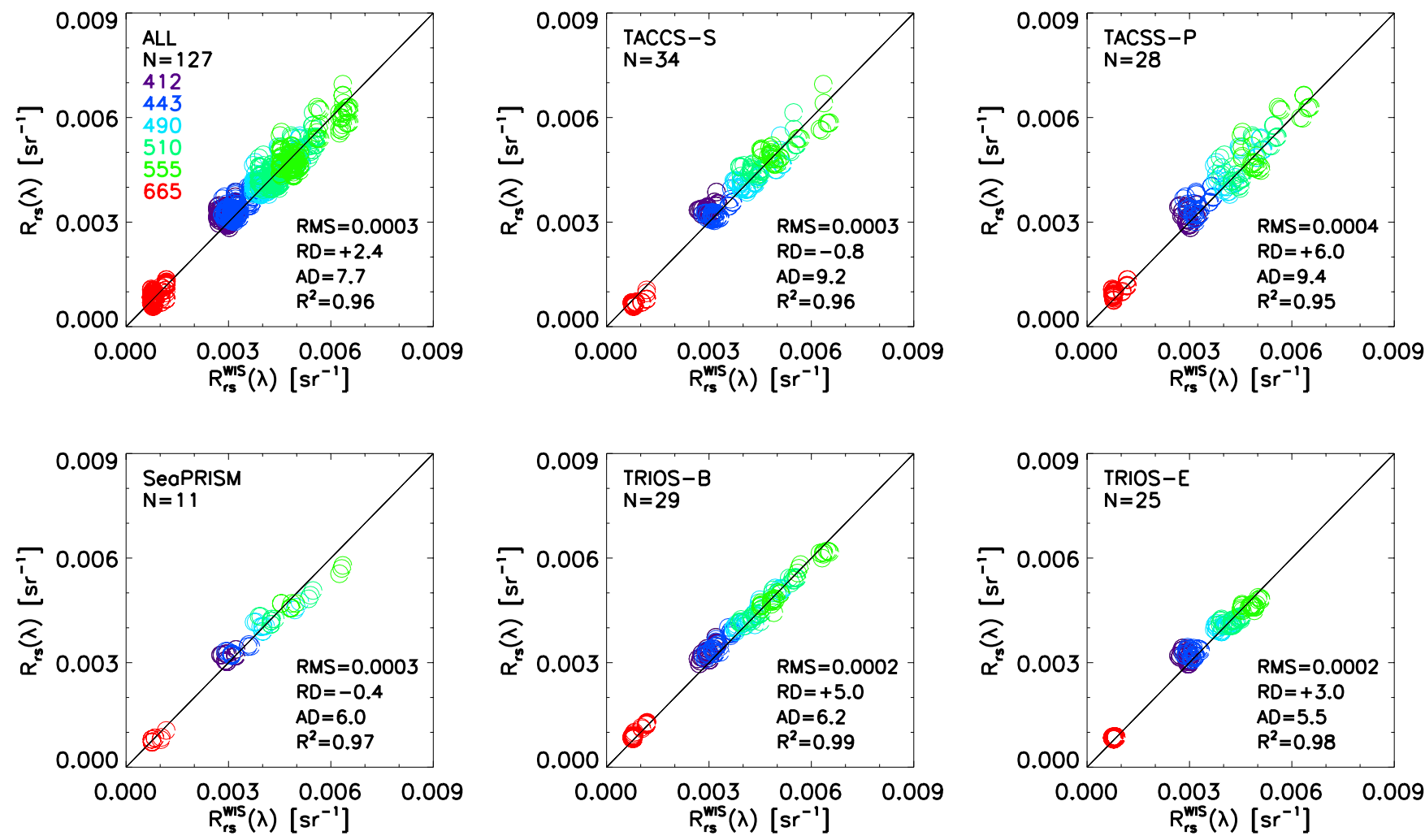

Fig. 4. As in Fig. 2 but for $R_{\mathrm{rs}}(\lambda)$.

\subsection{Discussion}

Results for the ARC inter-comparison illustrate the best that can be achieved with the considered systems/methods under almost ideal measurement circumstances driven by favourable deployment capabilities as offered by the stability of the AAOT platform (i.e. making $E_{\mathrm{d}}\left(0^{+}, \lambda\right)$ measurements unaffected by tilt, when performed from the main superstructure), almost ideal environmental conditions characterized by relatively low sun zenith angles, clear sky and moderately low sea state, and finally inter-calibration of measurement systems. By solely considering this latter element, it is recalled that the inter-calibration removes potential biases in derived radiometric products generated by out-of-date or inaccurate calibrations. The comparison of absolute coefficients obtained at the JRC during the inter-calibration with those previously applied for the various systems included in ARC has shown minimum differences of $1-2 \%$ but also values exceeding $4 \%$ for individual radiometers. These second relatively high differences, if not removed, would significantly degrade the inter-comparison for one of the considered systems/methods.

Processing of data from in-water systems/methods requires values of $a(\lambda)$ and $c(\lambda)$. Differently, processing of data from above-water systems/methods requires values $W$ and $\mathrm{Chl} a$. The impact of uncertainties of these input quanti- ties is accounted for in the $R_{\mathrm{rs}}(\lambda)$ uncertainty budget for each system/method. It is however of interest to evaluate the impact of important quantities such as Chl $a$ utilized to correct for the off-nadir viewing geometry of $L_{\mathrm{w}}(\theta, \Delta \phi, \lambda)$. In the present exercise Chl $a$ was determined for all systems using a regional algorithm (see Berthon and Zibordi, 2004) applied to $R_{\mathrm{rs}}(\lambda)$ ratios. The average and the standard deviation of values computed for ARC measurements are $1.9 \pm 0.2 \mu \mathrm{g} 1^{-1}$. The corresponding values for actual concentrations determined from water samples through High Performance Liquid Chromatography (HPLC) are $0.9 \pm 0.3 \mu \mathrm{g} 1^{-1}$. The analysis of TRIOS-B data indicates that the different $\mathrm{Chl} a$ estimates give viewing angle corrections differing by less than $1 \%$ for $\Delta \phi=135^{\circ}$ and varying between 1 and $4 \%$ for $\Delta \phi=90^{\circ}$. However, the overall effect on $R_{\mathrm{rs}}(\lambda)$ inter-comparisons is well within the assumed uncertainties. In fact, when using measured Chl $a$ instead of the computed values, TRIOSE, TRIOS-B and SeaPRISM results indicate an increase of $0.5 \%, 0.9 \%$ and $1.2 \%$, respectively, for the spectrally averaged RD, and no significant change for the other statistical quantities. Differences among spectrally averaged RD for the various systems/methods are explained by the different measurement sequences included in the inter-comparison comprising diverse viewing geometries.

In order to evaluate the consistency of the overall intercomparison results illustrated in Sect. 4, Table 13 displays 
Table 10. Spectral values of the statistical indices (i.e. RMS, RD, AD and $R^{2}$ ) quantifying the inter-comparison results for $L_{\mathrm{W}}(\lambda)$ at the 443 , 555 and $665 \mathrm{~nm}$ center-wavelengths for the various systems/methods with respect to WiSPER.

\begin{tabular}{|c|c|c|c|c|c|c|c|c|c|c|c|c|c|}
\hline & \multirow[b]{2}{*}{$N$} & \multicolumn{4}{|c|}{443} & \multicolumn{4}{|c|}{555} & \multicolumn{4}{|c|}{665} \\
\hline & & RMS & $\mathrm{RD}$ & $\mathrm{AD}$ & $R^{2}$ & RMS & $\mathrm{RD}$ & $\mathrm{AD}$ & $R^{2}$ & RMS & $\mathrm{RD}$ & $\mathrm{AD}$ & $R^{2}$ \\
\hline TACCS-S & 34 & 0.02 & 0.2 & 3.1 & 0.87 & 0.04 & -2.9 & 4.5 & 0.90 & 0.02 & -20.0 & 20.0 & 0.85 \\
\hline TACCS-P & 28 & 0.04 & 8.8 & 9.7 & 0.67 & 0.06 & 7.9 & 8.2 & 0.91 & 0.02 & 21.3 & 21.5 & 0.81 \\
\hline SeaPRISM & 11 & 0.03 & 1.5 & 5.1 & 0.07 & 0.04 & 1.1 & 4.1 & 0.88 & 0.01 & -3.6 & 7.1 & 0.56 \\
\hline TRIOS-B & 29 & 0.03 & 5.7 & 5.9 & 0.92 & 0.02 & 1.6 & 2.5 & 0.98 & 0.01 & 12.3 & 12.3 & 0.96 \\
\hline TRIOS-E & 25 & 0.03 & 5.4 & 6.1 & 0.61 & 0.02 & 1.8 & 2.8 & 0.82 & 0.01 & 10.4 & 10.4 & 0.67 \\
\hline
\end{tabular}

Table 11. As in Table 10 but for $E_{\mathrm{d}}\left(0^{+}, \lambda\right)$.

\begin{tabular}{|c|c|c|c|c|c|c|c|c|c|c|c|c|c|}
\hline & \multirow[b]{2}{*}{$N$} & \multicolumn{4}{|c|}{443} & \multicolumn{4}{|c|}{555} & \multicolumn{4}{|c|}{665} \\
\hline & & RMS & $\mathrm{RD}$ & $\mathrm{AD}$ & $R^{2}$ & RMS & $\mathrm{RD}$ & $\mathrm{AD}$ & $R^{2}$ & RMS & $\mathrm{RD}$ & $\mathrm{AD}$ & $R^{2}$ \\
\hline TACCS-S & 34 & 4.5 & -1.2 & 2.7 & 0.85 & 6.0 & -2.5 & 3.4 & 0.76 & 4.9 & 1.8 & 3.6 & 0.75 \\
\hline TACCS-P & 28 & 8.8 & 1.7 & 6.0 & 0.48 & 13.1 & 7.5 & 8.1 & 0.41 & 10.2 & 5.5 & 6.7 & 0.38 \\
\hline SeaPRISM & 11 & 3.5 & -2.3 & 2.3 & 0.91 & 8.7 & 6.2 & 6.2 & 0.87 & 2.6 & 2.0 & 2.0 & 0.89 \\
\hline TRIOS-B & 29 & 3.8 & -1.8 & 2.6 & 0.92 & 5.4 & 3.2 & 3.2 & 0.86 & 4.0 & 1.2 & 1.7 & 0.82 \\
\hline TRIOS-E & 25 & 2.8 & -0.5 & 1.6 & 0.95 & 7.4 & 5.2 & 5.2 & 0.91 & 4.6 & 3.0 & 3.0 & 0.89 \\
\hline
\end{tabular}

Table 12. As in Table 10 but for $R_{\mathrm{rs}}(\lambda)$.

\begin{tabular}{|c|c|c|c|c|c|c|c|c|c|c|c|c|c|}
\hline & \multirow[b]{2}{*}{$N$} & \multicolumn{4}{|c|}{443} & \multicolumn{4}{|c|}{555} & \multicolumn{4}{|c|}{665} \\
\hline & & RMS & $\mathrm{RD}$ & $\mathrm{AD}$ & $R^{2}$ & RMS & $\mathrm{RD}$ & $\mathrm{AD}$ & $R^{2}$ & RMS & $\mathrm{RD}$ & $\mathrm{AD}$ & $R^{2}$ \\
\hline TACCS-S & 34 & 0.0002 & 1.6 & 4.5 & 0.54 & 0.0004 & -0.2 & 6.1 & 0.68 & 0.0002 & -21.2 & 21.2 & 0.66 \\
\hline TACCS-P & 28 & 0.0004 & 7.5 & 8.7 & 0.17 & 0.0005 & 0.9 & 7.8 & 0.65 & 0.0002 & 15.4 & 16.1 & 0.61 \\
\hline SeaPRISM & 11 & 0.0002 & 3.8 & 5.7 & 0.68 & 0.0004 & -4.8 & 6.0 & 0.94 & 0.0001 & -5.5 & 7.6 & 0.67 \\
\hline TRIOS-B & 29 & 0.0003 & 7.6 & 7.7 & 0.83 & 0.0002 & -1.5 & 2.7 & 0.96 & 0.0001 & 11.0 & 11.0 & 0.95 \\
\hline TRIOS-E & 25 & 0.0002 & 5.9 & 5.9 & 0.01 & 0.0002 & -3.3 & 3.9 & 0.36 & 0.0001 & 7.2 & 7.2 & 0.17 \\
\hline
\end{tabular}

Table 13. Average values of the absolute of relative percent differences (AD) determined for $R_{\mathrm{rs}}(\lambda)$ at the 443, 555 and $665 \mathrm{~nm}$ center-wavelengths for the various systems/methods with respect to WiSPER, and combined uncertainties (CU) determined from the statistical composition of uncertainties quantified for $R_{\mathrm{rs}}(\lambda)$ derived from WiSPER and from each other inter-compared system/method. Underlined values indicate AD significantly greater than the computed CU values.

\begin{tabular}{lcccccccc}
\hline & \multicolumn{3}{c}{ AD [\%] } & & \multicolumn{3}{c}{ CU [\%] } \\
\cline { 2 - 4 } \cline { 7 - 9 } & 443 & 555 & 665 & & 443 & 555 & 665 \\
\hline TACCS-S & 4.5 & 6.1 & $\underline{21.2}$ & & 8.3 & 8.0 & 9.3 \\
TACCS-P & 8.7 & 7.8 & $\underline{16.1}$ & & 8.4 & 7.7 & 8.8 \\
SeaPRISM & 5.7 & 6.0 & $\frac{7.6}{}$ & & 6.9 & 6.0 & 11.0 \\
TRIOS-B & 7.7 & 2.7 & $\underline{11.0}$ & & 8.0 & 5.5 & 6.7 \\
TRIOS-E & 5.9 & 3.9 & & 7.2 & & 8.0 & 5.5 & 6.7 \\
\hline
\end{tabular}

spectral AD values determined for $R_{\mathrm{rs}}(\lambda)$ at the 443, 555 and $665 \mathrm{~nm}$ center-wavelengths for the various systems/methods with respect to WiSPER, and the combined spectral uncertainties (CU) determined from the statistical composition of uncertainties quantified for WiSPER $R_{\mathrm{rs}}(\lambda)$ and for each other inter-compared system/method.

Recognizing that the computed CU values are overestimated by at least $1 \%$ due to the inter-calibration of the various systems, the comparison is a way to evaluate the consistency of the uncertainty budgets quantified for each system/method. The agreement between $\mathrm{AD}$ and $\mathrm{CU}$ values adds confidence to the uncertainty values estimated for each system/method. As expected, the largest differences between $\mathrm{AD}$ and $\mathrm{CU}$ values are observed at $665 \mathrm{~nm}$ for a few systems/methods (see underlined values in Table 13). By pointing out that the low values of $R_{\mathrm{rs}}(\lambda)$ at $665 \mathrm{~nm}$ (on the average 6 times lower than those observed at $555 \mathrm{~nm}$ ) might easily lead to higher percent differences in the inter-comparison results with respect to shorter wavelengths, the largest $A D$ 
(with respect $\mathrm{CU}$ values) are explained by biases affecting $L_{\mathrm{w}}(665)$ with respect to WiSPER products (assumed as true within the stated uncertainties). It is recalled that the analysis of RD for $L_{\mathrm{w}}(665)$ presented in Sect. 4 has indicated a systematic underestimate of $20 \%$ for TACCS-S and, a systematic overestimate of $21 \%$ for TACCS-P and of $12 \%$ for TRIOS-B.

\section{Summary and conclusions}

The agreement of spectral water-leaving radiance $L_{\mathrm{w}}(\lambda)$, above-water downward irradiance $E_{\mathrm{d}}\left(0^{+}, \lambda\right)$ and remote sensing reflectance $R_{\mathrm{rS}}(\lambda)$ determined from various measurement systems and methods has been investigated within the framework of a field inter-comparison called Assessment of In Situ Radiometric Capabilities for Coastal Water Remote Sensing Applications (ARC), carried out in the northern Adriatic Sea. Taking advantage of the geometrically favourable deployment conditions offered by the Acqua Alta Oceanographic Tower, measurements were performed under almost ideal environmental conditions (i.e. clear sky, relatively low sun zeniths and moderately low sea state) with a variety of measurement systems embracing multispectral and hyperspectral optical sensors as well as in- and abovewater methods. All optical sensors involved in the experiment were inter-calibrated through absolute calibration performed with the same standards and methods. Data products from the various measurement systems/methods were directly compared to those from a single reference system/method. Overall, inter-comparison results indicate an expected better performance for systems/methods relying on stable deployment platforms and thus exhibiting lower uncertainties in $E_{\mathrm{d}}\left(0^{+}, \lambda\right)$. Results for $R_{\mathrm{rs}}(\lambda)$ indicate spectrally averaged relative differences generally within -1 and $+6 \%$. Spectrally averaged values of the absolute differences are approximately $6 \%$ for the above-water systems/methods, and increase to $9 \%$ for the buoy-based systems/methods. The general agreement of this latter spectral $R_{\mathrm{rs}}(\lambda)$ uncertainty index with the combined uncertainties of inter-compared systems/methods is notable. This result undoubtedly confirms the consistency of the evaluated data products and provides confidence in the capability of the considered systems/methods to generate radiometric products within the declared range of uncertainties. However, it must be recalled that all measurements were performed under almost ideal conditions and for a limited range of environmental situations. Additionally, all the optical sensors benefitted from a common laboratory radiometric inter-calibration. These elements are specific to the ARC activity, and there is no assurance of achieving equivalent results with the considered systems and methods when using fully independent absolute radiometric calibrations, performing deployments from ships rather than grounded platforms (where applicable), or carrying out measurements during more extreme environ- mental conditions (e.g. elevated sun zenith angles, high sea state, water column characterized by near-surface gradient of optical properties, partially cloudy sky). This final consideration further supports the relevance and need for regular inter-comparison activities as best practice to comprehensively investigate uncertainties of measurements devoted to the validation of primary satellite ocean color products and mainly those that are going to be included in common repositories (e.g. MERIS Matchup In situ Database (MERMAID) and SeaWiFS Bio-optical Archive and Storage System (SeaBASS)).

\section{Appendix A}

\section{Acronyms}

\begin{tabular}{|c|c|}
\hline AAOT & Acqua Alta Oceanographic Tower \\
\hline ARC & $\begin{array}{l}\text { Assessment of In Situ Radiometric } \\
\text { Capabilities for Coastal Water Re- } \\
\text { mote Sensing Applications }\end{array}$ \\
\hline CEOS & $\begin{array}{l}\text { Committee on Earth Observation } \\
\text { Satellites }\end{array}$ \\
\hline ESA & European Space Agency \\
\hline FAFOV & Full-Angle Field of View \\
\hline IVOS & $\begin{array}{l}\text { Infrared and Visible Optical Sys- } \\
\text { tems }\end{array}$ \\
\hline JRC & Joint Research Centre \\
\hline MERIS & $\begin{array}{l}\text { Medium-Resolution Imaging Spec- } \\
\text { trometer }\end{array}$ \\
\hline MVT & MERIS Validation Team Meeting \\
\hline SeaPRISM & $\begin{array}{l}\text { SeaWiFS Photometer Revision for } \\
\text { Incident Surface Measurements }\end{array}$ \\
\hline SeaWiFS & Sea-Wide Field of View Sensor \\
\hline TACCS & $\begin{array}{l}\text { Tethered Attenuation Chain Colour } \\
\text { Sensors }\end{array}$ \\
\hline TRIOS & TriOS Optical System \\
\hline WGCV & Working Group Cal/Val \\
\hline WiSPER & $\begin{array}{l}\text { Wire-Stabilized Profiling Environ- } \\
\text { mental Radiometer }\end{array}$ \\
\hline
\end{tabular}




\section{Appendix B}

\section{Symbols of most used quantities}

\begin{tabular}{|c|c|c|}
\hline Symbol & Units & Definition \\
\hline$a(\lambda)$ & $\mathrm{m}^{-1}$ & $\begin{array}{l}\text { Spectral } \\
\text { absorption } \\
\text { coefficient of } \\
\text { seawater }\end{array}$ \\
\hline$a_{\mathrm{y}}(\lambda)$ & $\mathrm{m}^{-1}$ & $\begin{array}{l}\text { Spectral } \\
\text { absorption } \\
\text { coefficient }\end{array}$ \\
\hline & & $\begin{array}{l}\text { of yellow } \\
\text { substance }\end{array}$ \\
\hline$b(\lambda)$ & $\mathrm{m}^{-1}$ & $\begin{array}{l}\text { Spectral scat- } \\
\text { tering coeffi- } \\
\text { cient of sea- } \\
\text { water }\end{array}$ \\
\hline$c(\lambda)$ & $\mathrm{m}^{-1}$ & $\begin{array}{l}\text { Spectral } \\
\text { beam- } \\
\text { attenuation } \\
\text { coefficient of } \\
\text { seawater }\end{array}$ \\
\hline Chl $a$ & $\mu g 1^{-1}$ & $\begin{array}{l}\text { Concentration } \\
\text { of total } \\
\text { chlorophyll } a\end{array}$ \\
\hline$E_{\mathrm{d}}(z, \lambda, t)$ & $\mathrm{mW} \mathrm{cm}{ }^{-2} \mu \mathrm{m}^{-1}$ & $\begin{array}{l}\text { Spectral } \\
\text { downward } \\
\text { irradiance at } \\
\text { generic depth } \\
z \text { and time } t\end{array}$ \\
\hline$E_{\mathrm{d}}\left(z_{i}, \lambda, t\right)$ & $\mathrm{mW} \mathrm{cm}{ }^{-2} \mu \mathrm{m}^{-1}$ & $\begin{array}{l}\text { Spectral } \\
\text { downward } \\
\text { irradiance at } \\
\text { discrete depth } \\
z_{i} \text { and time } t\end{array}$ \\
\hline$E_{\mathrm{d}}\left(0^{+}, \lambda\right)$ & $\mathrm{mW} \mathrm{cm}{ }^{-2} \mu \mathrm{m}^{-1}$ & $\begin{array}{l}\text { Spectral } \\
\text { above-water } \\
\text { downward } \\
\text { irradiance } \\
\text { (implicitly at } \\
\text { time } t_{0} \text { ) }\end{array}$ \\
\hline$E_{\mathrm{d}}\left(0^{-}, \lambda\right)$ & $\mathrm{mW} \mathrm{cm} \mathrm{cm}^{-2}$ & $\begin{array}{l}\text { Spectral } \\
\text { downward } \\
\text { irradiance } \\
\text { at depth } 0^{-} \\
\text {(implicitly at } \\
\text { time } t_{0} \text { ) }\end{array}$ \\
\hline$E_{\mathrm{d}}\left(0^{+}, \lambda, t\right)$ & $\mathrm{mW} \mathrm{cm}{ }^{-2} \mu \mathrm{m}^{-1}$ & $\begin{array}{l}\text { Spectral } \\
\text { above-water } \\
\text { downward } \\
\text { irradiance at } \\
\text { generic time } t\end{array}$ \\
\hline$E_{\mathrm{d}}\left(0^{+}, \lambda, t_{0}\right)$ & $\mathrm{mW} \mathrm{cm}{ }^{-2} \mu \mathrm{m}^{-1}$ & $\begin{array}{l}\text { Spectral } \\
\text { above-water } \\
\text { downward } \\
\text { irradiance at } \\
\text { time } t_{0}\end{array}$ \\
\hline
\end{tabular}

\begin{tabular}{|c|c|c|}
\hline Symbol & Units & Definition \\
\hline$E_{\mathrm{d}}\left(0^{-}, \lambda, t, \theta_{\mathrm{s}}\right)$ & $\mathrm{mW} \mathrm{cm}{ }^{-2} \mu \mathrm{m}^{-1}$ & $\begin{array}{l}\text { Spectral } \\
\text { downward } \\
\text { irradiance at } \\
\text { depth } 0^{-} \text {, } \\
\text { time } t \text { and } \\
\text { apparent sun } \\
\text { angle } \theta_{\mathrm{s}}\end{array}$ \\
\hline $\bar{E}_{\mathrm{d}}\left(z_{i}, \lambda, t_{0}\right)$ & $\mathrm{mW} \mathrm{cm}{ }^{-2} \mu \mathrm{m}^{-1}$ & $\begin{array}{l}\text { Average } \\
\text { of multi- } \\
\text { ple spectral } \\
\text { downward } \\
\text { irradiance } \\
\text { values at } \\
\text { discrete depth } \\
z_{i} \text { and time } t_{0} .\end{array}$ \\
\hline$E_{\mathrm{S}}\left(\theta_{0}, \phi_{0}, \lambda\right)$ & $\mathrm{mW} \mathrm{cm}{ }^{-2} \mu \mathrm{m}^{-1}$ & $\begin{array}{l}\text { Spectral } \\
\text { direct sun } \\
\text { irradiance }\end{array}$ \\
\hline$E_{\mathrm{u}}(z, \lambda, t)$ & $\mathrm{mW} \mathrm{cm}^{-2} \mu \mathrm{m}^{-1}$ & $\begin{array}{l}\text { Spectral } \\
\text { upward ir- } \\
\text { radiance at } \\
\text { depth } z \text { and } \\
\text { time } t\end{array}$ \\
\hline$E_{\mathrm{u}}\left(z, \lambda, t_{0}\right)$ & $\mathrm{mW} \mathrm{cm}{ }^{-2} \mu \mathrm{m}^{-1}$ & $\begin{array}{l}\text { Spectral } \\
\text { upward ir- } \\
\text { radiance at } \\
\text { generic depth } \\
z \text { and time } t_{0}\end{array}$ \\
\hline$E_{\mathrm{u}}\left(0^{-}, \lambda\right)$ & $\mathrm{mW} \mathrm{cm}{ }^{-2} \mu \mathrm{m}^{-1}$ & $\begin{array}{l}\text { Spectral } \\
\text { upward ir- } \\
\text { radiance } \\
\text { depth at } \\
\text { (implicitly at } \\
\text { time } t_{0} \text { ) }\end{array}$ \\
\hline$E_{0}(\lambda)$ & $\mathrm{mW} \mathrm{cm}{ }^{-2} \mu \mathrm{m}^{-1}$ & $\begin{array}{l}\text { Mean extra- } \\
\text { atmospheric } \\
\text { spectral sun } \\
\text { irradiance }\end{array}$ \\
\hline$K_{\mathrm{d}}(\lambda)$ & $\mathrm{m}^{-1}$ & $\begin{array}{l}\text { Spectral } \\
\text { diffuse atten- } \\
\text { uation coef- } \\
\text { ficient from } \\
\text { multi-depth } \\
E_{\mathrm{d}}(z, \lambda, t)\end{array}$ \\
\hline$K_{1}(\lambda)$ & $\mathrm{m}^{-1}$ & $\begin{array}{l}\text { Spectral } \\
\text { diffuse atten- } \\
\text { uation coef- } \\
\text { ficient from } \\
\text { multi-depth } \\
L_{\mathrm{u}}(z, \lambda, t)\end{array}$ \\
\hline$K_{\mathrm{u}}(\lambda)$ & $\mathrm{m}^{-1}$ & $\begin{array}{l}\text { Spectral } \\
\text { diffuse atten- } \\
\text { uation coef- } \\
\text { ficient from } \\
\text { multi-depth } \\
E_{\mathrm{u}}(z, \lambda, t)\end{array}$ \\
\hline$K_{\Im}(\lambda)$ & $\mathrm{m}^{-1}$ & $\begin{array}{l}\text { Generic spec- } \\
\text { tral diffuse at- } \\
\text { tenuation co- } \\
\text { efficient }\end{array}$ \\
\hline
\end{tabular}




\begin{tabular}{|c|c|c|}
\hline Symbol & Units & Definition \\
\hline$L_{i}\left(\theta^{\prime}, \Delta \phi, \lambda\right)$ & $\mathrm{mW} \mathrm{cm}^{-2} \mu \mathrm{m}^{-1} \mathrm{sr}^{-1}$ & $\begin{array}{l}\text { Spectral sky- } \\
\text { radiance at } \\
\text { viewing angle } \\
\theta^{\prime} \text { and relative } \\
\text { azimuth } \Delta \phi \\
\text { (implicitly at } \\
\text { time } t_{0} \text { ) }\end{array}$ \\
\hline$L_{\mathrm{T}}(\theta, \Delta \phi, \lambda)$ & $\mathrm{mW} \mathrm{cm}{ }^{-2} \mu \mathrm{m}^{-1} \mathrm{sr}^{-1}$ & $\begin{array}{l}\text { Spectral total } \\
\text { above surface } \\
\text { sea-radiance } \\
\text { at viewing } \\
\text { angle } \theta \text { and } \\
\text { relative az- } \\
\text { imuth } \Delta \phi \\
\text { (implicitly at } \\
\text { time } t_{0} \text { ) }\end{array}$ \\
\hline$L_{\mathrm{u}}(z, \lambda, t)$ & $\mathrm{mW} \mathrm{cm}{ }^{-2} \mu \mathrm{m}^{-1} \mathrm{sr}^{-1}$ & $\begin{array}{l}\text { Spectral } \\
\text { upwelling } \\
\text { radiance at } \\
\text { generic depth } \\
z \text { and time } t\end{array}$ \\
\hline$L_{\mathrm{u}}\left(z, \lambda, t_{0}\right)$ & $\mathrm{mW} \mathrm{cm}{ }^{-2} \mu \mathrm{m}^{-1} \mathrm{sr}^{-1}$ & $\begin{array}{l}\text { Spectral } \\
\text { upwelling } \\
\text { radiance at } \\
\text { generic depth } \\
z \text { and time } t_{0}\end{array}$ \\
\hline$L_{\mathrm{u}}\left(z_{0}, \lambda, t\right)$ & $\mathrm{mW} \mathrm{cm}{ }^{-2} \mu \mathrm{m}^{-1} \mathrm{sr}^{-1}$ & $\begin{array}{l}\text { Spectral } \\
\text { upwelling } \\
\text { radiance at } \\
\text { fixed depth } z_{0} \\
\text { and time } t\end{array}$ \\
\hline$L_{\mathrm{u}}\left(0^{-}, \lambda\right)$ & $\mathrm{mW} \mathrm{cm} \mathrm{cm}^{-2} \mu \mathrm{m}^{-1} \mathrm{sr}^{-1}$ & $\begin{array}{l}\text { Spectral } \\
\text { upwelling } \\
\text { radiance at } \\
\text { depth } 0^{-} \\
\text {(implicitly at } \\
\text { time } t_{0} \text { ) }\end{array}$ \\
\hline $\bar{L}_{\mathrm{u}}\left(z_{0}, \lambda, t_{0}\right)$ & $\mathrm{mW} \mathrm{cm}{ }^{-2} \mu \mathrm{m}^{-1} \mathrm{sr}^{-1}$ & $\begin{array}{l}\text { Average of } \\
\text { multiple spec- } \\
\text { tral upwelling } \\
\text { radiance val- } \\
\text { ues at fixed } \\
\text { depth } z_{0} \text { and } \\
\text { time } t_{0}\end{array}$ \\
\hline$L_{\mathrm{w}}(\lambda)$ & $\mathrm{mW} \mathrm{cm}{ }^{-2} \mu \mathrm{m}^{-1} \mathrm{sr}^{-1}$ & $\begin{array}{l}\text { Spectral } \\
\text { water-leaving } \\
\text { radiance (im- } \\
\text { plicitly at } 0^{+} \\
\left.\text {and time } t_{0}\right)\end{array}$ \\
\hline $\bar{L}_{\mathrm{W}}(\theta, \Delta \phi, \lambda)$ & 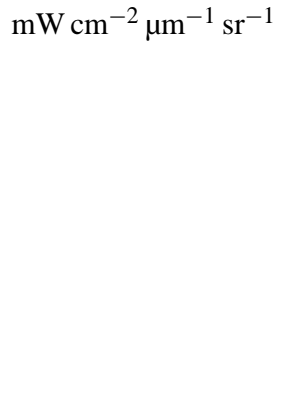 & $\begin{array}{l}\text { Average } \\
\text { of multi- } \\
\text { ple spectral } \\
\text { water-leaving } \\
\text { radiance } \\
\text { values at } \\
\text { viewing angle } \\
\theta \text { and relative } \\
\text { azimuth } \Delta \phi \\
\text { (implicitly at } \\
\text { time } t_{0} \text { ) }\end{array}$ \\
\hline
\end{tabular}

\begin{tabular}{|c|c|c|}
\hline Symbol & Units & Definition \\
\hline$L_{\mathrm{wn}}(\lambda)$ & $\begin{array}{l}\mathrm{mW} \mathrm{cm} \mathrm{cm}^{-2} \\
\mu \mathrm{m}^{-1} \mathrm{sr}^{-1}\end{array}$ & $\begin{array}{l}\text { Spectral } \\
\text { normalized } \\
\text { water-leaving } \\
\text { radiance (im- } \\
\text { plicitly at } 0^{+} \\
\text {and time } t_{0} \text { ) }\end{array}$ \\
\hline$Q\left(\theta, \Delta \phi, \theta_{0}, \lambda, \tau_{\mathrm{a}}, \mathrm{IOP}\right)$ & $\mathrm{sr}$ & Q-factor \\
\hline$Q_{\mathrm{n}}\left(\theta_{0}, \lambda, \tau_{\mathrm{a}}, \mathrm{IOP}\right)$ & $\mathrm{sr}$ & $\begin{array}{l}\text { Q-factor at } \\
\text { nadir view } \\
\text { (i.e. } \theta=0 \text { ) }\end{array}$ \\
\hline$r(\lambda)$ & - & $\begin{array}{l}\text { Ratio of } \\
\text { diffuse to } \\
\text { direct spectral } \\
\text { downward } \\
\text { irradiance } \\
\text { (implicitly at } \\
0^{+} \text {and time } \\
t_{0} \text { ) }\end{array}$ \\
\hline$R_{\mathrm{rS}}(\lambda)$ & $\mathrm{sr}^{-1}$ & $\begin{array}{l}\text { Spectral re- } \\
\text { mote sensing } \\
\text { reflectance } \\
\text { (implicitly at } \\
0^{+} \text {and time } \\
t_{0} \text { ) }\end{array}$ \\
\hline$R_{\mathrm{rs}}^{\prime}(\theta, \Delta \phi, \lambda)$ & $\mathrm{sr}^{-1}$ & $\begin{array}{l}\text { Spectral re- } \\
\text { mote sensing } \\
\text { reflectance at } \\
\text { viewing angle } \\
\theta \text { and relative } \\
\text { azimuth } \Delta \phi\end{array}$ \\
\hline$t$ & sec & Generic time \\
\hline$t_{0}$ & sec & $\begin{array}{l}\text { Reference } \\
\text { time }\end{array}$ \\
\hline$t_{\mathrm{d}}(\lambda)$ & - & $\begin{array}{l}\text { Spectral at- } \\
\text { mospheric } \\
\text { diffuse trans- } \\
\text { mittance }\end{array}$ \\
\hline TSM & $\mathrm{g} \mathrm{m}^{-3}$ & $\begin{array}{l}\text { Total sus- } \\
\text { pended matter }\end{array}$ \\
\hline$W$ & $\mathrm{~m} \mathrm{~s}^{-1}$ & Wind speed \\
\hline$z$ & $\mathrm{~m}$ & Generic depth \\
\hline$z_{i}$ & $\mathrm{~m}$ & $\begin{array}{l}\text { Discrete } \\
\text { depth }\end{array}$ \\
\hline$z_{0}$ & $\mathrm{~m}$ & Specific depth \\
\hline$\theta$ & degrees & $\begin{array}{l}\text { Viewing } \\
\text { angle }\end{array}$ \\
\hline$\theta_{0}$ & degrees & $\begin{array}{l}\text { Sun zenith an- } \\
\text { gle }\end{array}$ \\
\hline$\theta_{\mathrm{s}}$ & degrees & $\begin{array}{l}\text { Apparent sun } \\
\text { zenith angle }\end{array}$ \\
\hline$\theta^{\prime}$ & degrees & $\begin{array}{l}\text { Viewing an- } \\
\text { gle defined as } \\
180-\theta\end{array}$ \\
\hline$\lambda$ & $\mathrm{nm}$ & Wavelength \\
\hline$\rho\left(\theta, \Delta \phi, \theta_{0}, W\right)$ & - & $\begin{array}{l}\text { Sea surface } \\
\text { reflectance }\end{array}$ \\
\hline
\end{tabular}




\begin{tabular}{|c|c|c|}
\hline Symbol & Units & Definition \\
\hline$\rho^{\prime}(W)$ & - & $\begin{array}{l}\text { Sea surface reflectance (defined as a } \\
\text { function of } W \text { only) }\end{array}$ \\
\hline$\tau_{\mathrm{a}}(\lambda)$ & - & Spectral aerosol optical thickness \\
\hline$\Delta \phi$ & degrees & $\begin{array}{l}\text { Relative azimuth between sun and } \\
\text { sensor }\end{array}$ \\
\hline$\Re(\theta, W)$ & - & $\begin{array}{l}\text { Sea surface reflection/refraction } \\
\text { factor }\end{array}$ \\
\hline $\mathfrak{R}_{0}$ & - & $\begin{array}{l}\text { Sea surface reflection/refraction } \\
\text { factor at } \theta=0\end{array}$ \\
\hline
\end{tabular}

Acknowledgements. Jean-Paul Huot and Philippe Goryl from ESA are duly acknowledged for the support provided to the ARC activity within the framework of the MERIS Validation Team activities. The authors are equally grateful to Nigel Fox, chair of the IVOS subgroup of CEOS-CVWG, for stimulating the activity and managing any related administrative issues. The authors also wish to thank the NASA AERONET team led by Brent Holben for the continuous effort in supporting AERONET-OC. Acknowledgments are finally due to Jean-François Berthon, Elisabetta Canuti, Lukasz Jankowski, José Beltrán and Agnieszka Bialek for the support provided during various phases of the inter-comparison. Kevin Ruddick's participation was partially funded by the Belgian Science Policy Office STEREO Programme under the BELCOLOUR-2 (SR/00/104) contract. Tartu Observatory and Stockholm University contributions were partially supported by the EU FP7 Marie Curie Actions - Industry-Academia Partnerships and Pathways (IAPP) through the WaterS project (Grant Agreement 251527). The four reviewers are all acknowledged for their detailed and constructive comments contributing to improve the paper.

Edited by: O. Zielinski

\section{References}

Achard, F., Eva, H. D., Stibig, H. J., Mayaux, P., Gallego, J., Richards, T., and Malingreau, J.P.: Determination of deforestation rates of the world's humid tropical forests, Science, 297, 999-1002, 2002.

Austin, R. W.: The remote sensing of spectral radiance from below the ocean surface, in: Optical Aspects of Oceanography, Academic Press, 1974.

Barton, I. J., Minnet, P. J., Maillet, K. A., Donlon, C. J., Hook, S. J., Jessup, A. T., and Nightingale, T. J.: The Miami2001 Infrared Radiometer Calibration and Intercomparison. Part II: Shipboard Results, J. Atmos. Ocean. Tech., 21, 268-283, 2004.

Behrenfeld, M. J., O’Malley, R. T., Siegel, D. A., McClain, C. R., Sarmiento, J. L., Feldman, G. C., Milligan A. J., Falkowski, P. G., Letelier, R. M., and Boss, E. S.: Climate-driven trends in contemporary ocean productivity, Nature, 444, 752-755, 2006.

Berthon, J.-F. and Zibordi, G.: Bio-optical relationships for the northern Adriatic Sea, Int. J. Remote Sens., 25, 1527-1532, 2004.

Bird, R. E. and Riordan, C. J.: Simple solar spectral model for direct and diffuse irradiance on horizontal and tilted planes at the Earth's surface for cloudless atmospheres, J. Clim. Appl. Meteorol., 25, 87-97, 1986.
Brando, V. E. and Dekker, A. G.: Satellite hyperspectral remote sensing for estimating estuarine and coastal water quality, IEEE Trans. Geosc. Rem. Sens., 41, 1378-1387, 2003.

D'Alimonte, D., Zibordi, G., Kajiyama, T., and Cunha, J. C.: A Monte Carlo code for high spatial resolution ocean color simulations, Appl. Optics, 49, 4936-4950, 2010.

Deschamps, P.-Y., Fougnie, B., Frouin, R., Lecomte, P., and Verwaerde, C.: SIMBAD: a field radiometer for satellite ocean-color validation, Appl. Optics, 43, 4055-4069, 2004.

Doyle, J. P. and Zibordi, G.: Optical propagation within a 3dimensional shadowed atmosphere-ocean field: application to large deployment structures, Appl. Optics, 41, 4283-4306, 2002.

Fougnie, B., Frouin, R., Lecomte, P., and Deschamps, P. Y.: Reduction of skylight reflection effects in the above-water measurement of diffuse marine reflectance, Appl. Optics, 38, 3844-3856, 1999.

Gordon, H. and Clark, D. K.: Clear water radiances for atmospheric correction of Coastal Zone Color Scanner imagery, Appl. Optics, 20, 4175-4180, 1981

Gordon, H. and Ding, K.: Self-shading of in-water optical measurements, Limnol. Oceanogr., 37, 491-500, 1992.

Gould, R. W., Arnone, R. A., and Sydor, M.: Absorption, scattering, and remote sensing reflectance relationships in coastal waters: Testing a new inversion algorithm, J. Coastal Res., 17, 328-341, 2001.

Hooker, S. B. and Zibordi, G.: Platform perturbation in AboveWater Radiometry, Appl. Optics, 44, 553-567, 2005.

Hooker, S. B., Lazin, G., Zibordi, G., and McClean, S.: An evaluation of above- and in-water methods for determining water leaving radiances, J. Atmos. Ocean. Tech., 19, 486-515, 2002a.

Hooker, S. B., McLean, S., Small, M., Lazin, G., Zibordi, G., and Brown, J.: The Seventh SeaWiFS Intercalibration RoundRobin Experiment (SIRREX-7), March 1999. SeaWiFS Report NASA/TM-2001-206892, vol. 17, edited by: Hooker, S. B. and Firestone, E. R., NASA Goddard Space Flight Center, Greenbelt, Maryland, 2002b.

Hooker, S. B., Zibordi, G., Berthon, J.-F., and Brown, J. W.: AboveWater Radiometry in shallow coastal waters, Appl. Optics, 43 , 4254-4268, 2004.

Iqbal, M.: An Introduction to Solar Radiation, Academic Press, Canada, 1983.

Kaufman, Y. J., Tanré, D., and Boucher, O.: A satellite view of aerosols in the climate system, Nature, 419, 215-223, 2002.

Kirk, J. T. O.: Light \& Photosynthesis in Aquatic Ecosystems, 2nd Edition, Cambridge University Press, UK, 1994.

Kratzer, S., Brockmann, C., and Moore, G.: Using MERIS full resolution data ( $300 \mathrm{~m}$ spatial resolution) to monitor coastal waters - a case study from Himmerfjärden, a fjord-like bay in the northwestern Baltic Sea, Remote Sens. Environ., 112, 2284-2300, 2008.

Leathers, R. A., Downes, T. V., and Mobley, C. D.: Self-shading correction for upwelling sea-surface radiance measurements made with buoyed instruments, Opt. Express, 8, 561-570, 2001.

Loisel, H. and Morel, A.: Light scattering and chlorophyll concentration in Case 1 waters: A reexamination, Limnol. Oceanogr. 43, 847-858, 1998.

Mobley, C. D.: Light and Water, Academic Press, San Diego, USA, 1994.

Mobley, C. D.: Hydrolight 4.0 Users Guide DTIC Document, 1998. 
Mobley, C. D.: Estimation of the remote sensing reflectance from above-water methods, Appl. Optics, 38, 7442-7455, 1999.

Moore, G. F., Icely, J. D., and Kratzer, S.: Field Inter-comparison and validation of in-water radiometer and sun photometers for MERIS validation, Proceedings of the ESA Living Planet Symposium, Special Publication SP-686, 2010.

Morel, A. and Antoine, D.: Heating rate within the upper ocean in relation to its bio-optical state, J. Phys. Oceanogr., 24, 16521665, 1994

Morel, A., Antoine, D., and Gentili, B.: Bidirectional reflectance of oceanic waters: accounting for Raman emission and varying particle scattering phase function, Appl. Optics, 41, 6289-6306, 2002.

Mueller, J. L., Pietras, C., Hooker, S. B., Clark, D. K., Morel, A., Frouin, R., Mitchell, B. G., Bidigare, R. R., Trees, C., Werdell, J., Fargion, G. S., Arnone, R., Austin, R. W., Bailey, S., Broenkow, W., Brown, S. W., Carder, K., Davis, C., Dore, J., Feinholz, M., Flora, S., Lee, Z. P., Holben, B., Johnson, B. C., Kahru, M., Karl , D. M., Kim, Y. S., Knobelspiesse, K. D., McClain, C. R., McLean, S., Miller, M., Mobley, C. D., Porter, J., Steward, R. G., Stramska, M., Van Heukelem, L., Voss, K., Wieland, J., Yarbrough, M. A., and Yuen, M.: Ocean Optics Protocols for Satellite Ocean Color Sensor Validation, Revision 3. NASA/TM2002-210004/Rev3, Greenbelt, NASA Goddard Space Flight Center, 2002.

Petzold, T. J.: Volume scattering functions for selected ocean waters, Scripps Institution of Oceanography, SIO Ref. 72-78, 1972.

Ruddick, K., De Cauwer, V., and Van Mol, B.: Use of the near infrared similarity spectrum for the quality control of remote sensing data. SPIE international conference 5885 on "Remote Sensing of the Coastal Oceanic Environment", San Diego, 2005.

Ruddick, K., De Cauwer, V., Park, Y., and Moore, G.: Seaborne measurements of near infrared water-leaving reflectance - the similarity spectrum for turbid waters, Limnol. Oceanogr., 51, 1167-1179, 2006.

Ruddick, K., Lacroix, G., Lancelot, C., Nechad, B., Park, Y., Peters, S., and Van Mol, B.: Optical remote sensing of the North Sea, in: Remote sensing of the European Seas, edited by: Barale, V. and Gade, M., Springer Science + Business Media B. V., 79-90, 2008.

Stroeve, J., Holland, M. M., Meier, W., Scambos, T., and Serreze, M.: Arctic sea ice decline: Faster than forecast, Geophys. Res. Lett., 34, L09501, doi:10.1029/2007GL029703, 2007.

Stumpf, R. P. and Tomlinson, M. C.: Remote sensing of harmful algae blooms, in: Remote sensing of coastal aquatic environments: technologies, techniques and applications, edited by: Miller, R., Castillo, C. D., and McKee, B., Kluwer, 2005.

Thome, K., Schiller, S., Conel, J., Arai, K., and Tsuchida, S.: Results of the 1996 Earth Observing System vicarious calibration joint campaign to Lunar Lake Playa, Nevada (USA), Metrologia, 35, 631-638, 1998.

Thuillier, G., Hersé, M., Labs, D., Foujols, T., Peetermans, W., Gillotay, D., Simon, P. C., and Mandel, H.: The solar spectral irradiance from 200 to $2400 \mathrm{~nm}$ as measured by the SOLSPEC spectrometer from the Atlas and Eureca missions, Solar Phys., 214, 1-22, 2003.
Zaneveld, J. R., Boss, V. E., and Barnard, A.: Influence of surface waves on measured and modeled irradiance profiles, Appl. Optics, 40, 1442-1449, 2001.

Zibordi, G.: Immersion factor of in-water radiance sensors: assessment for a class of radiometers, J. Atmos. Ocean. Tech., 23, 302313, 2006.

Zibordi, G.: Comment on "Long Island Sound Coastal Observatory: assessment of above-water radiometric measurement uncertainties using collocated multi and hyperspectral systems", Appl. Optics, 51, 3888-3892, 2012.

Zibordi, G. and Bulgarelli, B.: Effects of cosine error in irradiance measurements from field ocean color radiometers, Appl. Optics, 46, 5529-5538, 2007.

Zibordi, G. and Ferrari, G. M.: Instrument self shading in underwater optical measurements: experimental data, Appl. Optics, 34, 2750-2754, 1995.

Zibordi, G., Doyle, G. P., and Hooker, S. B.: Offshore tower shading effects on in-water optical measurements, J. Atmos. Ocean. Tech., 16, 1767-1779, 1999.

Zibordi, G., Berthon, J.-F., Doyle, J. P., Grossi, S., van der Linde, D., Targa, C., and Alberotanza, L.: Coastal Atmosphere and Sea Time Series (CoASTS), Part 1: A long-term measurement program. NASA Tech. Memo. 2002-206892, v. 19, edited by: Hooker, S. B. and Firestone, E. R., NASA Goddard Space Flight Center, Greenbelt, Maryland, 29 pp., 2002a.

Zibordi, G., Hooker, S. B., Berthon, J.-F., and D'Alimonte, D.: Autonomous above-water radiance measurement from an offshore platform: A field assessment, J. Atmos. Ocean. Tech., 19, 808819, 2002 b.

Zibordi, G., D'Alimonte, D., and Berthon, J.-F.: An evaluation of depth resolution requirements for optical profiling in coastal waters, J. Atmos. Ocean. Tech., 21, 1059-1073, 2004a.

Zibordi, G., Mélin, F., Hooker, S. B., D'Alimonte, D., and Holben, B.: An autonomous above-water system for the validation of ocean color radiance data, IEEE Trans. Geosc. Rem. Sens., 42, 401-415, 2004b.

Zibordi, G., Mélin, F., and Berthon, J.-F.: Comparison of SeaWiFS, MODIS and MERIS radiometric products at a coastal site, Geophys Res. Lett., 33, L06617, doi:10.1029/2006GL025778, 2006.

Zibordi, G., Berthon, J.-F., and D'Alimonte, D.: An evaluation of radiometric products fixed-depth and continuous in-water profile data from a coastal site, J. Atmos. Ocean. Tech., 26, 91-186, 2009a.

Zibordi, G., Berthon, J.-F., Mélin, F., D’Alimonte, D., and Kaitala, S.: Validation of satellite ocean color primary products at optically complex coastal sites: Northern Adriatic Sea, Northern Baltic Proper and Gulf of Finland, Remote Sens. Environ., 113, 2574-2591, 2009b.

Zibordi, G., Holben, B., Slutsker, I., Giles, D., D’Alimonte, D, Mélin, F., Berthon, J.-F., Vandemark, D., Feng, H., Schuster, G., Fabbri, B.E., Kaitala, S., and Seppälä, J.: AERONET-OC: a network for the validation of Ocean Color primary radiometric products, J. Atmos. Ocean. Tech., 26, 1634-1651, 2009c. 